\author{
Federal Reserve Bank of Dallas \\ Globalization and Monetary Policy Institute \\ Working Paper No. 275 \\ http://www.dallasfed.org/assets/documents/institute/wpapers/2016/0275.pdf
}

\title{
Breaking Down World Trade Elasticities: a Panel ECM Approach*
}

\author{
Jaime Martinez-Martin \\ Banco de España
}

June 2016

\begin{abstract}
This paper exhaustively analyses the recent decline of international trade elasticities to output growth. We extend an empirical model of import demand functions to account not only for transitory factors, such as relative prices and import intensity-adjusted measures of demand (I-O Tables), but also for habitually neglected permanent factors such as protectionism, vertical integration (i.e. Global Value Chains) and foreign direct investment (FDI). Dealing with a non-stationary heteregenous panel of 27 countries, we estimate a panel Error Correction Model from 1960 to 2015 in order to break down world trade elasticities. Our main findings evidence: i) the presence of panel (cointegrating) structural changes in the trade-to-GDP relationship in 2000 and 2009, private consumption being a source of disruption; ii) although investment and exports are the most sensitive, import-intensive components of demand, this is far from being transitory, which is clearly weighing on the current slowdown; iii) the relevant contribution of GVCs shows a procyclical pattern, questioning the permanent nature of the current levelling-off of vertical integration processes. The lack of progress in reducing import tariffs and the usual discarded, complementary relationship between FDI and imports have a residual role. All in all, our results have substantial policy implications, as they reinforce the idea of a historical break towards a new 'normal' trading phase.
\end{abstract}

JEL codes: F14, F40, C23

\footnotetext{
* Jaime Martinez-Martin, Banco de España, Alcala 48 28014, Madrid, Spain. jaime.martinezm@bde.es. The views in this paper are those of the author and do not necessarily reflect the views of the Bank of Spain, the Eurosystem, the Federal Reserve Bank of Dallas or the Federal Reserve System.
} 


\section{Introduction}

Trade flows collapsed during the so-called 'Great Recession' of 2009 more than ever, prompting a huge shock to economic agents. The sudden and grave downturn in global trade was followed by a remarkable rebound and a phase of anaemic growth from 2010. In recent years, higher trade ratios (i.e. rising openness) have led to more trade-sensitive economies, which are facing higher spillover effects due to greater trade (inter)dependence. In addition, trade monitoring has become paramount since it has emerged as a channel for knowledge transfer and for specialisation based on comparative advantages, thereby improving resource allocation and supporting higher economic growth and welfare (real incomes) over time. ${ }^{1}$

As a result, it is not surprising that the relationship between business cycles and trade flows has been a relevant, long-standing question, which has received renewed attention given that the recent trade slowdown and its future evolution are becoming a real "puzzle". Policymakers and scholars are unanimously questioning whether the protracted global trade-to-GDP ratio of $60 \%$ registered repeateadly since 2011 - according to the World's Bank World Development Indicators database - might represent an actual ceiling (See Figure 1). The upshot of this evolution lies at the heart of the debate. In a nutshell, the current time-invariant global trade-to-GDP ratio has been both theoretically and empirically explained by the related literature through a breakdown of transitory against permanent factors, or a combination of both. The question is whether the current situation is simply a reflection of the weak world business cycle or whether some other structural factors are also playing a role.

The easy but unclear answer would be a combination of both. Yet our empirical approach tries to shed some light on these hypotheses by quantifying the actual contribution to import growth of selected transitory (i.e. import-adjusted demand, relative import prices) and permanent factors (namely protectionism, vertical integration and foreign direct investment [FDI]). For the sake of simplicity, we firstly test the presence of (panel) structural breaks in trade-to-GDP elasticity over time, under a usually neglected long-term cointegrating framework. Secondly, we estimate a panel dynamic Error Correction Model (ECM) to break down the recent decline in global trade elasticities into transitory and permanent factors, therefore constituting the first attempt to relate both branches of the related literature.

The first strand of the literature builds up the transitory (cyclical) factors behind the recent slowdown in global trade. Some papers invoke the change in the composition of aggregate demand (Bussière et al. 2013) while others focus on the weakness in intra-euro area trade (the EU trade

\footnotetext{
${ }^{1}$ See, for instance, Baldwin (2011) and Hoekman (2015).
} 
bloc accounts for one-third of total world trade). In this regard, what has really been special in the current trade slowdown period is that it has been mainly driven by emerging economies. ${ }^{2}$ (See Figure 2). A regional decomposition of trade elasticities demonstrates that the shift in relative growth from advanced economies towards emerging market economies has caused a considerable decline in the elasticity of global imports in recent years, since import elasticity is noticeably lower in emerging market economies (Slopek, 2015).

On the other side, there are quite diverse potential factors of a permanent (i.e. structural) nature that may have led to the recent global trade slowdown. First, a slowdown in the expansion of global value chains (GVCs) is likely to have a persistent dampening impact (Constantinescu et al. 2015). ${ }^{3}$ However, while supply chain specialists predict that there will be a move away from highly fragmented, globe-spanning supply chains towards a greater reliance on regional product networks (Srinivasan et al. 2014, Stank et al. 2014), others disagree and argue that the trade slowdown is more pronounced for products where participation in GVCs is more prevalent (Ferrantino and Taglioni, 2014). ${ }^{4}$ Second, the rise in government support for domestic industries (i.e. protectionism), for example by increasing non-tariff barriers such as quality standards or health regulations. Third, the end of integration processes in China and central/eastern Europe. Fourth, the change in the composition of global trade towards products with lower elasticity (trade-income). And last but not least, the potential substitution effect of higher stocks of inward FDI in domestic demand for imports. This forgotten channel may have been playing a role in the recent trade slowdown, as raised by Barrell and Pain (1997) and in the special report on FDI by the WTO (1996). ${ }^{5}$

Our empirical strategy is based on the extension of import demand functions under a panel cointegrating framework. We revisit world trade elasticities and consider an empirical model of international trade flows in order to test for potential (transitory and permanent) determinants behind the recent decline in trade elasticities. In particular, we account for i) differences in competitiveness, proxied by relative import prices; ii) the higher disggregated import intensity-adjusted

\footnotetext{
${ }^{2}$ Due to data availability constraints and considering the homogeneity principle when addressing with trade figures, we were not able to include major emerging economies such as China, Brazil, India or Russia in our panel regressions.

${ }^{3}$ It may be interpreted as the absorption of past technology shocks, which have led to the fall of the share of imports of intermediate goods in certain emerging economies' merchandise exports, for instance.

${ }^{4}$ In any case, it may be too premature to conclude that structural expansion is over since it is a relatively recent phenomenon and there is potential for further trade liberalisation (Jääskela and Mathews, 2015).

${ }^{5}$ Other possible alternative explanations have come to the fore, such as a change in relative prices and productivity between tradable and non-tradable goods, statistical measurement errors that do not adequately reflect the current development of trade, the collapse of trade finance channels (BIS 2014), or the positive effects of technical progress that led trade momentum (i.e. containerisation). Needless to say, these explanations are neither exclusive nor exhaustive.
} 
measure of aggregate demand ${ }^{6}$, which has not been investigated after the Global Trade Collapse (GTC) by the related literature; iii) potential structural factors such as protectionism measures, vertical integration (as a proxy of GVCs) and the effect of the stock of inward FDI. To do so, we move to a neglected cointegrating framework and estimate a panel ECM, by dealing with a non-stationary (heteregeous) panel of 27 OECD countries from 1960Q1 to 2015Q1.7

Our main contributions may be summarised as follows. First, by means of panel cointegration tests of structural breaks with cross-dependence, we are able to detect at least two structural changes in long-run trade-to-GDP elasticities over time, particularly in 2000 and $2009^{8}$. Second, we find that the global long-term elasticity of trade with respect to income reverted back to even lower levels after the GTC. Third, in terms of GDP components, private consumption seems to be one of the main sources of structural breaking in the trade-to-GDP relationship. In this respect, we demonstrate that although exports and investment are the most sensitive, import-intensive components of demand, such evolution is far from being transitory and is clearly weighing on the current slowdown. ${ }^{9}$ Fourth, our empirical findings also suggest that permanent factors are playing an important role in the current regime. For instance, the contribution of GVCs to import growth has evolved quite procyclically in the last four years, questioning the current levelling-off of vertical integration to be of a permanent nature. To a lesser extent, the lack of progress in reducing import tariffs is statistically negligible, while a usually forgotten, complementary relationship between inward FDI and imports is also found, albeit with a rather small elasticity. Accordingly, these results have substantial policy implications, as they reinforce the idea of a historical breakpoint where longer-term factors are exerting influence at least as much as cyclical factors, heading to a new 'normal' trading regime.

The remainder of the paper is as follows. Section 2 reviews the related literature, emphasising those approaches trying to explain the recent trade slowdown under a global framework; Sect. 3 discusses the error correction dynamic panel model approach and panel cointregration tests with structural breaks, while Sect. 4 describes the data and provides stylised facts on the import content of GDP components, protectionist measures and GVCs; Sect. 5 highlights our main empirical results while Sect. 6 concludes.

\footnotetext{
${ }^{6}$ Based on OECD Input-Output tables.

${ }^{7}$ The choice of countries reflects data availability. In any case, they account for more than a half of world GDP in ppp, and for around 70\% of world trade, according to IMF, WEO April 2016 figures.

${ }^{8}$ Based on the very recently developed tests by Banerjee and Carrion-i-Silvestre (2015).

${ }^{9} \mathrm{In}$ line with the findings of the literature, firms often require specialised capital goods with usually more direct access from overseas than locally (see, for instance, Bems et al. (2013)).
} 


\section{Related literature: the "suspects" behind the world trade slowdown}

This paper ties in with the preceding literature on the recent attempt to disentangle the current trade slowdown and the decline in global trade elasticities between transitory and permanent factors. We revisit world trade elasticities under an import demand function framework, for which the excellent work of Constantinescu et al. (2015) provided a useful but incomplete assessment, as they acknowledge: "while we cannot directly test the relative importance of these factors, we provide some circumstantial evidence on how far each might have contributed to the observed slowdown". ${ }^{10}$ As a matter of fact, many of their arguments have been addressed more formally in the papers that we review below.

For the sake of simplicity, let us summarise the related literature solely drawing on the two strands mentioned above and an additional one: i) relative to stylised facts in the behaviour of the trade and GDP relationship; ii) those papers providing cyclical arguments behind the decline in trade elasticities, such as weaker global demand or the change in the composition of aggregate demand; iii) structural arguments. Needless to say, these explanations are neither exclusive nor exhaustive, they are simply a starting point.

First, a seminal strand of the literature has analysed the changes in the long-run relationship between trade and income following Irwin (2002). He summarised the variation of global trade elasticity between 1870 and 2000 and concluded that since the mid-1980s trade has been more responsive to income than in any other period under consideration, although he is not able to identify those factors behind such a high elasticity. Later on, Freund (2009) and Buono and Vergara-Caffarelli (2013) evidenced higher elasticities in times of crisis than in expansions, since demand shocks may cause extensive margins to be adjusted more than output. In contrast, Ollivaud and Schwellnus (2015) took as a stylised fact that the apparent elasticity tends to decrease in global recessions. ${ }^{11}$

A second strand of the literature argues that the change in the relationship is mainly cyclical, e.g. Boz et al. (2014), who suggest that most of the decline in trade is explained by cyclical

\footnotetext{
${ }^{10}$ Note that their definition of cyclical vs. structural factors is different to ours, as it refers to long vs. short-run properties of their country-speficic error correction models. A particular sub-section is devoted to this issue (Sect. $5.3)$.

${ }^{11}$ In the appendix we address this issue by estimating our empirical model including asymmetries. Our results suggest that at times in which import-adjusted demand decreases, its sensitivity to imports becomes higher than in expansion regimes. It supports, partially, the idea of a trade-off between domestic sales and imports during recession periods, but only in the shortrun.
} 
elements and they should disappear once the global recovery progresses further. Veenendaal et al. (2015) and ECB (2015) also argue that the recent trade dynamics are mainly non-permanent. The identified factors would, therefore, be linked to weak demand in some advanced economies (i.e. the Eurozone) and/or higher levels of uncertainty. A second explanation relates to composition effects in terms of elasticity variation, which may be due to changes in the composition of supply and demand that have led to an increased presence of components with lower trade intensity. This composition effect might be sectorial, geographical or of some other type. For instance, the seminal work of Bussière et al. (2013) suggests the existence of a composition effect on slowing growth of trade-related demand components as we discuss below with further details. Along these lines, there could also be a change in the composition of trade, with a greater weight of services and public spending and a lower presence of tradable goods.

With regard to permanent (i.e. structural) factors explaining the lower sensitivity of trade to production, mainly three can be mentioned. First, less intense fragmentation of the value chain internationally may cause a reduction in the intensity of trade to production, or what is equivalent to this, a reduction of international transactions for given production. Constantinescu et al. (2015) suggest that the vertical specialisation of the production process could be an important factor in determining the lesser responsiveness of trade to changes in income since the begining of the century. Thus, as stated by Ferrantino and Taglioni (2014), trade in complex goods typically associated with supply chains has grown particularly slowly after the GTC, suggesting that significant demand shocks can cause vertical specialisation to decrease, thereby reducing trade elasticities [in line with Buono and Vergara-Caffarelli (2013), Lejour et al. (2014) and Crozet et al. (2015)]. They approximate GVC trade essentially by 'imported intermediate goods' and evidence that GVC trade may have been a driver of the GTC as it fell significantly more than total trade; however, during the recent slowdown, they seem to be moving together. Therefore, one cannot conclude that GVC trade is an important driver of the recent slowdown in trade. An example is the Chinese case, since the effect of GVCs on its trade remains unclear in light of the evidence of Gangnes et al. (2014): increased elasticity is due to composition effects rather than greater integration in the value chain.

A second permanent factor commonly used refers to a resurgence of protectionism (for example, by advancing non-tariff barriers such as quality standards or health regulations) or, in this respect, to a slower advance of the liberalisation and trade integration processes with respect to prior periods. Evenett (2014) and Evenett and Fritz (2015) consider that there may be effects of protectionism in certain sectors and countries, while Boz et al. (2014) go a step further and suggest that the effects of protectionism are more important than those related to the value chain as the former improve productivity. However, other authors attribute a marginal role to the resurgence 
of protectionism, such as Constantinescu et al. (2015), although they note that less progress in liberalisation could also have an effect on trade developments.

A third structural factor has to do with the change in the regional composition of long-term elasticities. For instance, the shift in relative growth from advanced economies towards emerging market economies has caused a considerable decline in the elasticity of global imports in recent years according to Slopek (2015) and Stratford (2015). Other authors, such as Constantinescu et al. (2015) or Gaulier et al. (2015), pointed to composition elements related to specific countries (i.e. China or Europe) while Escaith and Miroudot (2015) tried to focus on the consequences of the process of convergence between developed and developing countries.

\subsection{Why the related literature may be unsatisfactory}

It is first worth mentioning that our bottom-up approach has been built upon country-specific and panel estimates of import functions, based on previous findings of Garcia et al. (2009) for Spain, and extended to a panel framework following an import intensity adjusted by GDP components approach of Bussière et al. (2013). Yet their results should not be entangled by long-run elasticities since they ignore the non-stationarity and heterogenous features of their panel, and omit the longrun panel cointegrating relationship that data show. ${ }^{12}$ Additionaly, the assumption of homogeneity of slope parameters is inappropiate, meaning that their fixed-effects estimation approach could be used only if intercepts were allowed to differ across groups. One must bear in mind that if the slope coefficients are not identical, the fixed-effects estimates may produce inconsistent and misleading results. To resolve this crucial issue, we estimate a non-stationary dynamic panel error correction model, in which the parameters are heterogeneous across groups. As our second main reference, we also follow a similar approach to that of Constantinescu et al. (2015). However, they fell also short in omitting Marquez's (1999) warnings: 'using standard measures of aggregate demand, such as GDP or domestic demand, in trade equations may be misleading', as they do in their country-speficic error correction models. To evidence the magnitude of the "tragedy", Figure 3 reports import demand elasticities when aggregate demand is proxied by GDP [(as in Constantinescu et al. (2015)] against those obtained by using an import-adjusted measure based on GDP components. Our results suggest that there has been an obvious overestimation of import

\footnotetext{
${ }^{12}$ Westerlund (2007) error-correction-based panel cointegration test results clearly reject the null Ho of no cointegration in their dataset. For instance, with 27 series and 2 covariates (import-adjusted demand and relative prices), the $G_{t}$ statistic value is equal to -2.07 , with an associated $p-$ value of 0.003 .
} 
demand elasticities in recent years ${ }^{13}$, with particular dampening effects during the trade collapse. ${ }^{14}$ Figure 4 shows evidence of the different fits of country-specific ECMs when using GDP, domestic demand or our measure of import-adjusted demand (for the US, UK, Japan and Germany). In addition, the approach of Constantinescu et al. (2015) did not deal with heterogeneous features of a panel framework, building uncorrelated country-specific models and estimating structural breaks, which are not statistically consistent under a global context. To tackle this caveat, we follow cointegration tests of structural breaks under a panel framework based on Banerjee and Carrioni-Silvestre (2015), which confirm at least two structural breaks of long-run trade elasticities over time (2000 and 2009). The next sections provide details on our empirical approach.

\section{The econometric strategy}

\subsection{Trade elasticities estimation}

To begin with, we define an empirical structure based on short and long-run determinants of import volumes based on our theoretical underpinning, which is the standard constant elasticity of substitution (CES) demand system. ${ }^{15}$ Against this backdrop, we establish a production possibilities frontier setting to demonstrate the theoretical foundation of our empirical approach. ${ }^{16}$ Yet in contrast to the recent literature and to the best of our knowledge, this is the first attempt to adopt a dynamic panel error correction model based on the estimation of non-stationary heterogenous panels, in which the main focus will be on the extension of our import demand function $\left(M_{i, t}\right) .{ }^{17}$ We assume the following long-run import demand function:

$$
M_{i, t}=\alpha_{o t}+\beta_{1} I A D_{i, t}+\beta_{2} R M P_{i, t}+\beta_{3} F D I_{i, t}+\beta_{4} P T_{i, t}+\beta_{5} G V C_{i, t}+\mu_{i}+\epsilon_{i, t},
$$

where the number of countries $i=1,2, \ldots, N$; the number of periods $t=1,2, \ldots, T ; M_{i, t}$ is the import volumes series; $I A D_{i, t}$ is a weighted vector decomposing aggregate demand: exports $\left(X_{i, t}\right)$, private consumption $\left(C_{i, t}\right)$, government expenditure $\left(G_{i, t}\right)$ and total investment $\left(I N V_{i, t}\right)$ based on

\footnotetext{
${ }^{13}$ And more so in periods in which investment and exports (the most import-intensive components of GDP) substantially change.

${ }^{14}$ In this sense, it is worth highlighting that our income elasticities for the G7 countries using the GDP import demand approach are quite similar (at the begining of the sample) to the seminal work of Hooper et al (2000).

${ }^{15}$ Similar empirical approaches are used by Freund (2009), Escaith et al. (2010), European Commission (2012), Milberg and Winkler (2010), Bussière et al. (2013), Ollivaud and Schwellnus (2015), Constantinescu et al. (2015), and European Central Bank (2015).

${ }^{16}$ To illustrate the theoretical background of our import demand function with an unrestricted elasticity, please refer to the Appendix (Sect. 7.1).

${ }^{17}$ In the standard framework, the basket $M_{i, t}$ is itself a CES aggregate of individual imports.
} 
the import content intensity from the OECD Input-Output tables; $R P M_{i, t}$ is the relative import price indicator, reflecting competitiveness in terms of national vs. foreign prices; $F D I_{i, t}$ is the stock of inward capital flows to host country $i$; and $P T_{i, t}$ is a measure of protectionism based on Temporary Trade Barriers (TTBs), such as import tariffs, antidumping and countervailing duties. When it comes to vertical specialisation, we employ imported intermediate goods as a proxy of Global Value Chains $\left(G V C_{i, t}\right)$, based on OECD bilateral trade in goods database. All variables are expressed in logs except $P T_{i, t}$. Bear in mind that, if variables are $I(1)$ and cointegrated, then the error term would be $I(0)$ for all $i$. Therefore, for the sake of simplicity let us assume an $\operatorname{ARDL}(1,1,1)$ dynamic panel specification of $(1)$ :

$$
\begin{aligned}
M_{i, t}= & \delta_{10, i} I A D_{i, t}+\delta_{11, i} I A D_{i, t-1}+\delta_{20, i} R M P_{i, t}+\delta_{21, i} R M P_{i, t-1} \\
+ & \delta_{30, i} F D I_{i, t}+\delta_{31, i} F D I_{i, t-1}+\delta_{40, i} P T_{i, t}+\delta_{41, i} P T_{i, t-1} \\
& +\delta_{50, i} G V C_{i, t}+\delta_{51, i} G V C_{i, t-1}+\lambda_{i} M_{i, t-1}+\mu_{i}+\epsilon_{i, t},
\end{aligned}
$$

and the error correction reparametrisation of the previous equation once we allow for additional dynamics:

$$
\begin{gathered}
\Delta M_{t, i}=\alpha_{i}+\sum_{l=1}^{L} \beta_{j} \Delta I A D_{t-l, i}+\sum_{m=1}^{M} \delta_{m} \Delta R M P_{t-m, i} \\
+\sum_{n=1}^{N} \delta_{n} \Delta F D I_{t-n, i}+\sum_{p=1}^{P} \delta_{p} \Delta P T_{t-p, i}+\sum_{q=1}^{Q} \delta_{q} \Delta G V C_{t-q, i} \\
\left.-\gamma_{i}\left(M_{t-1, i}-\rho I A D_{t-1, i}+\mu R M P_{t-1, i}+\sigma F D I_{t-1, i}+\nu P T_{t-1, i}+w G V C_{t-1, i}\right)\right)+\epsilon_{i, t},
\end{gathered}
$$

where $\gamma_{i}=-\left(1-\lambda_{i}\right)$ reflects the speed of adjustment to long-run equilibrium and subscript $i$ denotes the country. One would expect $\gamma_{i}$ to be negative if the variables exhibit a return to their long-run equilibrium. Besides, several import function theories indicate that the long-run demand elasticity, $\rho$, should be equal to one. The relative prices effect, $\mu$, is generally thought to be negative. ${ }^{18}$ The elasticity of imports to demand is stable in our model because $I A D$ reflects the composition adjustments over time, tackling Marquez's critique as to the usefulness of the log-linear framework to estimate elasticities of trade to income, since trade openness may modify the domestic and foreign composition of expenditure. In this sense, under certain assumptions, aggregate demand takes the form of our IAD aggregator - in levels, a Cobb-Douglas function, with time-varying weights, of private consumption, investment, government consumption and exports.

\footnotetext{
${ }^{18}$ As observed in Eq. (1), it restricts the elasticiy of imports to aggregate demand to be equal to one. Nonetheless, in the Appendix, a derivation of a theoretical (log) import demand equation - allowing for unrestricted elasticity is provided for the sake of clarity. We allow for temporal deviations of the theoretical long-run equilibrium elasticity of one.
} 


\subsection{Panel cointregration tests with structural breaks and cross-section dependence}

Initial evidence indicates that there are serious grounds for accounting for structural instability when performing the cointegration analysis in the dataset as previously mentioned. In this sense, we try to shed some light on this controversial issue by testing heterogenous break dates based on Banerjee and Carrion-i-Silvestre (2015). Their recent test not only accounts for structural breaks in a panel cointegrating framework but also for cross-dependence. For the sake of simplicity, let $Y_{i, t}=\left(y_{i, t}, x_{i, t}^{\prime}\right)$ be an $(m \times 1)$ vector of non-stationary stochastic process whose elements are individually $I(1)$ and the structural form of the data-generating process (DGP) as:

$$
\begin{gathered}
Y_{i, t}=D_{i, t}+x_{i, t}^{\prime} \delta_{i, t}+\mu_{i, t} \\
\mu_{i, t}=F_{t}^{\prime} \pi_{i}+e_{i, t} \\
(I-L) F_{t}=C(L) w_{t} \\
\left(I-\rho_{i} L\right) e_{i, t}=H_{i}(L) \varepsilon_{i, t} \\
x_{i, t}=k_{i}+x_{i, t-1}+G_{t}^{\prime} \partial_{i}+\epsilon_{i}(L) v_{i, t} \\
G_{t}=\ell(L) \omega_{t}
\end{gathered}
$$

where $i=1, \ldots, N, t=1, \ldots, T$, where $C(L)=\sum_{j=0}^{\infty} C_{j} L^{j}, H_{i}(L)=\sum_{j=0}^{\infty} h_{i, j} L^{j}, \epsilon_{i}(L)=\sum_{j=0}^{\infty} \epsilon_{i, j} L^{j}$ and $\ell(L)=\sum_{j=0}^{\infty} \ell_{i, j} L^{j}$. Therefore, given the deterministic term $D_{i, t}$, its general functional form is:

$$
D_{i, t}=\mu_{i, t}+\beta_{i} t+\sum_{j=1}^{m_{i}} \theta_{i, j} D U_{i, j, t}+\sum_{j=1}^{m_{i}} \gamma_{i, j} D T_{i, j, t}
$$

where $D U_{i, j, t}=1$ and $D T_{i, j, t}=\left(t-T_{i, j}^{b}\right)$ for $t>T_{i, j}^{b}$ and 0 otherwise, with $T_{i, j}^{b}=\lambda_{i, j}^{b} T$ denoting the timing of the $j$-th break, $j=1, \ldots, m_{i}$, for the $i$-th unit, $i=1, \ldots, N, \lambda_{i, j}^{b} \in \Lambda, \Lambda$ being a closed subset of $(0,1)$ according to Banerjee and Carrion-i-Silvestre (2015). We assume that our model does not contain a linear trend $-\beta_{i}=\gamma_{i, j}=0$ for all $i, j$ and $k_{i}=0$ for all $i$. However, the presence of multiple structural breaks affects both the level and the cointegrating vector of the panel ECM. ${ }^{19}$

\footnotetext{
${ }^{19} \mathrm{It}$ is worth mentioning that this framework becomes general enough to allow for multiple structural breaks affecting either the deterministic component or the cointegrating vector. The number of structural breaks with regard to the cointegrating vector $\left(n_{i}\right)$ might be different from the number of those affecting the deterministic component $\left(m_{i}\right)$. In the empirical arena, it is infeasible in practice unless the number of breaks is rather small.
} 


\section{Dataset and stylised facts}

We consider the following 27 countries: the G7-group (United States, United Kingdom, Japan, Germany, France, Italy and Canada), and Australia, Korea, Spain, The Netherlands, Portugal, Norway, New Zealand, Sweden, Belgium, Finland, Denmark, Austria, Greece, Hungary, Iceland, Israel, Mexico, Slovenia, Switzerland and Ireland. Tha dataset spans the period running from 1960Q1 to 2015Q1, and is provided by the OECD. Table 1 reports descriptive statistics for quarterly changes.

Imports are measured in terms of volumes and refer to both goods and services. Domestic demand is constructed by using input-output tables, whereby weights of each demand component correspond to its country-specific share. The relative price (competitiveness) indicators are also country-specific, calculated as the log difference of national - GDP deflator - vs. import prices. Other price measures such as the consumer price index (CPI) or unit labour costs in total economy (ULCT) were discarded owing to homogenous data availability constraints.

Following Bussière et al. (2013) and Boz et al. (2014) we have explored OECD Input-Output tables, which are available with a considerable delay. For instance, in 2016 we are only able to explore the most recent data as of 2011. Therefore, we have inferred equal values from 2011 onwards, and similarly, from 1985 backwards, applying the corresponding caution in the results. Thus, as shown in Figure 5, the import content of GDP components in our sample has evolved in recent years as follows. Investment continues to be the most import-intensive component of GDP, while exports and private consumption have gradually gained traction in recent years. In this connection, it is obvious that the trade intensity of different components of aggregate demand has varied insofar as changes in composition have become more plausible. For the sake of robustness, we have applied an interpolation strategy between input-output table releases. The results suggest that there are no significant variations against our weighting scheme.

In line with Ferrantino and Taglioni (2014), we have employed intermediate imported goods as a proxy of GVCs. The original source from 1990 up to 2015 is the OECD bilateral trade database. ${ }^{20}$ Additionaly, we have used two sources of information on protectionism. First, the Global Trade Alert (GTA), an independent initiative coordinated by the CEPR. The GTA maintains a comprehensive database of trade with regard to TTBs, such as import tariffs, anti-dumping and countervailing duties. However, since the geographical coverage is rather limited, we have employed an alternative database of the World Bank based on Bown (2012). ${ }^{21}$ The share of imports subject

\footnotetext{
${ }^{20}$ We have converted annual figures into quarterly figures.

${ }^{21}$ We have interpolated annual figures into quarterly figures up until the latest available data on the share of import products subject to imposed TTBs, which is 2014 .
} 
to any TTB in effect have been increasing steadily worldwide. ${ }^{22}$

In terms of time series analysis, we have performed tests for identifying the order of integration both for individual series and within a panel framework. Our findings suggest that all real variables are $I(1)$, whereas the presence of a unit root is not so straightforward to identify in the case of certain relative import prices. However, following Dieppe and Warmedinger (2007), we assume that these variables are $I(1)$ and suitable for cointegration analysis.

\section{Empirical results}

\subsection{Transitory vs. permanent factors}

An initial set of empirical results are derived from the panel ECM estimates of Table 2. In columns (1), (2), (3), and (4), the coefficient related to long-run import demand elasticity goes from a positive and statistically significant value to a moderate-sized elasticity. It supports the previous idea: an overestimation of income elasticities has been occuring whenever GDP or domestic demand approaches are employed instead of an import-adjusted demand measure. In column (5) there is a breakdown of demand component elasticities. As expected by its higher import-content, exports become the most import-sensitive component. Our estimates of trade-to-GDP elasticities in the long-run are in line with those of Bussière et al. (2013) in terms of the magnitude of different demand measures. ${ }^{23}$ In Table 3, inward stock of FDI, protectionist measures and GVCs are sequentially added in the panel regression. Three lessons may be extracted from those results. First, stock inward FDI may be mantaining a complementary relationship with imports, but one of rather limited relevance. Second, protectionism is playing a negligible role in the trade slowdown in the longrun, in contrast of Constantinescu et al. (2015), whose long-term component explains the greater part when decomposing trade growth. ${ }^{24}$ Third, the relationship between GVCs and imports is positive and statistically relevant, which may reinforce the argument of vertical integration (Blonigen et al. 2003, and Helpman et al. 2004).

Insofar as we are interested in common long-run elasticities, we have employed a pooled mean group (PMG) estimator. It allows for heterogenous short-run dynamics and common long-run elasiticities and it is based on the pooled mean-group estimator for dynamic heterogenous panels

\footnotetext{
${ }^{22}$ The limitations of this database are mainly two: i) measures are added to historical numbers as they are discovered, so the most recent observations should be revised upwards significantly.; ii) as warned by Boz et al. (2014) the data include 'behind-the-border' measures in addition to those that are directly targeted on trade.

${ }^{23}$ Domestic demand specification (1.44 against our 1.96), GDP specification (1.29 against our 1.72) and IAD specification (1.16 against our 1.37). Albe withit different time and country selection database.

${ }^{24}$ We devote a whole sub-section (5.3) to further research this issue.
} 
developed by Pesaran et al. (1999). Theoretically, import demand elasticity is usually restricted to one. However, when we test empirically the hypothesis $\rho(I A D)=1$, the corresponding $X^{2}$ value of 393.8 leads to a rejection of the null hypothesis of unit demand elasticity. Additionally, our PMG estimates could fail to be inconsistent if the null of slope homogenity is empirically rejected. To resolve this drawback, we have adopted a mean group (MG) estimation, meaning that the MG parameters are the unweigthed mean of the $N$ individual regression coefficients. ${ }^{25}$ Finally, we have restricted the coefficients of the cointegrating vector to be equal across all panels by estimating a traditional dynamic fixed-effects model. It also restricts the speed of adjustment coefficient and the short-run dynamics to be equal. ${ }^{26}$ Table 3 reports in columns (5) and (6) the corresponding MG and dynamic FE approaches. Results do not differ dramatically across statistical approaches.

In order to empirically test whether there is a change in the cyclical determinants, such as relative import prices and the composition of aggregate demand, whose effects may be weighing on global lower trade elasticities, we have opted for a two-fold strategy. First, by conducting 5-year rolling window estimates by demand components (Figure 6). And second, by breaking import growth down into import-adjusted demand components (Figure 7) and relative prices from 2005 onwards. As a result, we are able to quantify the contribution of both the weak recovery in the post-crisis period in the components of aggregate demand and the negligible effect of prices. The import growth decomposition of current figures demonstrates that although exports and investment have emerged as the most sensitive, import-intensive components of demand, this evolution is far from being transitory. In this respect, the private consumption contribution has been increasing over the last two years.

Based on Equation (3) estimates, Figure 8 reports the contributions to quarterly import growth of transitory and permanent factors, adding sequentially the GVCs. As can be observed, a procyclical pattern arises for GVCs, with positive and negative contributions over the last four years, which may lead a levelling off in global value chains to be discarded as a non-transitory factor. ${ }^{27}$ Yet, in light of these results, it would imply that the vertical specialisation approach might help little in disentangling transitory and permanent factors. On the other side, the most relevant cyclical factor contributing to the current slowdown is clearly import-adjusted demand.

\footnotetext{
${ }^{25}$ Based on Pesaran and Smith (1995).

${ }^{26}$ As discussed in Baltagi et al. (2000), these models are subject to a simultaneous equation bias from the engogeneity between the error term and the lagged dependent variable. However, our Hausmann test results indicate that this bias becomes minimal for our dataset.

${ }^{27}$ Although different methodological approaches and proxies for GVCs were employed, our results are in line with those of Borin and Mancini (2015).
} 


\subsection{Panel breaks: It's me not you, or have we both changed?}

First, it is worth mentioning that we test panel cointegrating structural breaks from 1990 to 2015 . This a crucial but unavoidable set up and one to be taken with caution since we are assuming a homogenous elasticity over the period 1960-1990. We have not been able to test the whole sample for two reasons. First, due to balanced-panel constraints, since we have tried to maximise the dimensions of our panel. Second, we have decided to use the longest panel dataset in order to satisfy the condition that the time dimension should be larger than the cross-section dimension. This means excluding Greece, Hungary, Israel, Mexico and Slovenia, and starting from January 1990 to April $2015(T=102)$.

The frequency of the estimated heterogeneous break dates (years and quarters) for 21 countries are summarised in Figure 9. As a result, three different regimes in the trade-GDP relationship emerge from the two obtained structural breakpoints. As can be seen, the estimated break dates are mostly placed around the incorporation of China into the global economy in 2000 and, secondly, by the end of 2009 reflecting the impact of the GTC.

However, it should be borne in mind that these estimated break dates do not necessarily lead to a consistent evolution of the GDP components since only imports, relative prices and our measure of import-adjusted demand have been considered. Based on this approach, Figure 10 reports component-specific panel cointegrating structural break dates. As mentioned above, the density of estimated break points for private consumption, investment and public expenditure are placed just around the same dates. In contrast, break dates for exports are quite asynchronous with the rest of the GDP components. In this respect, it is obvious that the evolution of exports has not contributed at all to either of the structural breaks of 2000 and 2009.

In addition, our analysis has proceeded assuming that all units define a cointegration relationship. However, the rejection of the null hypothesis of no panel cointegration does not necessarily mean that all the units of the panel are cointegrated. In this regard, the information drawn from the unit-by-unit analysis can be helpful in assessing the robustness of our conclusions. To this end, we have taken into account only the units for which the null hypothesis of no cointegration is rejected in the unit-by-unit analysis. Accordingly, in Figure 11 the densities of the estimated coefficients for the three regimes under the cointegrating relationship are summarised. They show signs that the same qualitative conclusions in terms of lower import-demand elasticities are found. Table 4 reports the in-sample country-specific estimates using the three alternative import demand measures.

To sum up, once we have defined the three different periods based on our structural break estimates (i.e., 1960-2000; 2001-2009; 2010-2015), Table 5 confirms that global long-term elasticities 
of trade with respect to income have reverted back to even lower levels after the GTC, in a context of lower relevance of short-term relative import prices. We have also tested the statistical crossdifferences of import-adjusted elasticities over time by generating multiplicative dummy variables for each regime already mentioned before, and implementing linear Wald tests. In all cases, $H_{0}$ : $\rho_{i, 1}-\rho_{i, 2}=0, H_{0}: \rho_{i, 1}-\rho_{i, 3}=0, H_{0}: \rho_{i, 2}-\rho_{i, 3}=0$, we can reject the null hypotheses of statistical homogeneity.

\subsection{Short vs. long-term determinants}

Figure 12 reports contributions of short and long-term determinants to import growth for the period 2005-2015 for the panel sample. The blue bars capture the short-term import growth predicted by the model, while the red bars represent the predicted long-run component of import growth. These results may yield useful insights. First, the short-run share of import growth tends to explain half of the total growth for most of the sample in contrast to Constantinescu et al. (2015). Second, the remaining portion, capturing permanent effects, dominates during the last two years, but not during periods of crisis such as the trade collapse in 2008 and 2009. The rationale for such findings is that even if the long-run trade elasticity is high and has decreased over time, trade tends to slowly adjust to its equilibrium, which offsets the impact of income shocks. As reported in Table 5 , the speed of adjustment to the long-run equilibrium for the period between 2010 and 2015 is -0.233 , rather slower than that in the previous period (-0.369).

\section{Concluding remarks}

This paper evaluates potential transitory and permanent factors behind the recent decline in global trade elasticities by means of an empirical model based on import demand functions. To the best of our knowledge, this is the first attempt to extend a reduced-form model of import demand functions to take in cyclical factors (i.e. relative prices and the new import intensity-adjusted measure of aggregate demand by GDP components by exploiting the information contained in the OECD Input-Output tables) and also permanent determinants (i.e. protectionist measures, vertical integration as a proxy of GVCs and the stock of inward FDI). Our second original contribution is to evidence the presence of the (usually neglected) long-term, cointegrating relationship between global trade and GDP, which has moreover been affected by (at least) two structural breaks in the last 25 years. Our empirical strategy is based on the estimation of a panel ECM, which allows us to quantify factor contributions to the current world trade slowdown Additionally, we test for panel structural breaks in the trade and income relationship, under a cointegrating and cross- 
section dependent framework within a non-stationary heteregeous panel of 27 (mostly advanced) economies from 1960 to 2015.

Our main empirical findings can be summarised as follows: i) our results suggest that at least two structural breakpoints (mostly neglected by the literature) should be considered across the board when it comes to long-term trade-to-GDP elasticities, in particular in 2000 and 2009. In this regard, private consumption seems to be a potential source of disruption whereas exports could be discarded; ii) permanent factors are playing an important role in the current regime of trade slowdown. For instance, the relevant contribution of GVCs to import growth have evolved quite procyclicaly in the last four years, questioning the permanent nature of the current levelling-off of vertical integration processes. To a lesser extent, a usually forgotten, complementary relationship between inward FDI and imports is also found, while the lack of progress in reducing import tariffs becomes statistically negligible; iii) however, some transitory factors cannot be discarded, especially behind the third regime (2010-2015). For instance, as long as exports and investment have become more trade-intensive than consumption, a persistent EU recovery (high trade-to-GDP ratio) may boost global trade not only in advanced but also in emerging economies. In this respect, we find that although exports and investment are the most sensitive components to import demand, this is far from being transitory and is clearly weighing on the current slowdown. All in all, these results have substantial policy implications, as they reinforce the idea of a historical break, towards a new 'normal' trading phase.

Future avenues of research should consider the supply of trade finance as a potential nontransitory factor and growth rebalancing in China from investment and exports to consumer spending. The amount of domestic value added in China's exports grows as processing trade declines, which would lead to "onshoring" by replacing imports with domestically produced goods. As a consequence, further research would be extremely useful to disentangle the insights of the current new 'normal' phase. 


\section{References}

[1] Barrel, R., and N. Pain (1997), "Foreign direct investment, technological change, and economic growth within Europe", The Economic Journal 107(445), pp. 1770-1786.

[2] Bems, R., Johnson, RC,. and K.M. Yi (2013), "The Great Trade Collapse", Annual Review of Economics 5(1), pp. 375-400.

[3] Bank for International Settlements (2014), "Trade finance: developments and issues", CGFS Publications No 50 .

[4] Banerjee, A., and J.Ll. Carrion-i-Silvestre (2015), "Cointegration in panel data with structural breaks and cross-section dependence", Journal of Applied Econometrics: 30, pp. 1-23.

[5] Baltagi, BH., Griffin, JM., and W. Xiong (2000), "To poool or not to pool: Homogeneous versus heterogeneous estimators applied to cigarette demand", Review of Economics and Statistics (82), pp. 117-126.

[6] Blonigen, BA., Davies, RB., and K. Head (2003), "Estimating the knowledge-capital model of the multinational enterprise: comment." American Economic Review 87(4), pp. 520-544.

[7] Borin, A., and M. Mancini (2015), "Follow the value added: bilateral gross export accounting", Bank of Italy, Working Paper 1026.

[8] Bown, C.P. (2012) Temporary Trade Barriers Database, The World Bank.

[9] Boz, E., Bussière, M., and C. Marsilli (2014), "Recent Slowdown in Global Trade: Cyclical or Structural", in B Hoekman (ed.), The Global Trade Slowdown: A New Normal?, A VoxEU eBook, London: CEPR Press and EUI.

[10] Buono, I., and F. Vergara-Caffarelli (2013), "Trade Elasticity and Vertical Specialization," Bank of Italy, Working Paper 924, July 2013.

[11] Bussière, M., G. Callegari, F. Ghironi, G. Sestieri and N. Yamano (2013), "Estimating trade elasticities: Demand elasticities and the trade collapse of 2008-09", American Economic Journal: Macroeconomics 5(3), pp. 118-151.

[12] Constantinescu, C., A. Mattoo, and M. Ruta (2015), "The Global Trade Slowdown: Cyclical or Structural?," IMF Working Paper No. 15/6. 
[13] Crozet, M., Emlinger, C., and S. Jean (2015), "On the gravity of world trade's slowdown", in B Hoekman (ed.), The Global Trade Slowdown: A New Normal?, A VoxEU eBook, London: CEPR Press and EUI.

[14] Dieppe, A., and T. Warmedinger (2007), "Modelling intra- and extra-area trade substitution and exchange rate pass-through in the euro area", ECB Working paper No. 760.

[15] European Central Bank (2015), "Understanding the weakness in world trade", ECB Econ Bulletin No. 3.

[16] European Commission (2012), "Has the crisis left a lasting mark on global trade?", Vol. 11 (2), EC Quarterly Report.

[17] Escaith, H., N. Lindenberg, and S. Miroudot (2010), "International supply chains and trade elasticity in times of global crisis". In: Cattaneo, O. et al. (eds) Global value chains in a postcrisis world: a development perspective. World Bank Publications, Washington.

[18] Escaith, H., and S. Miroudot (2015), "World trade and income remain exposed to gravity", in B Hoekman (ed.), The Global Trade Slowdown: A New Normal?, A VoxEU eBook, London: CEPR Press and EUI.

[19] Evenett, S. (2014), "The Global Trade Disorder", 14th GTA Report, London: CEPR Press.

[20] Evenett, S., and J. Fritz (2015), "Crisis-era trade distortions cut LDC export growth by 5.5\% per annum", in B Hoekman (ed.), The Global Trade Slowdown: A New Normal?, A VoxEU eBook, London: CEPR Press and EUI.

[21] Feenstra, RC. (2003), "Advanced international trade: theory and evidence", Princeton University Press.

[22] Feenstra, RC. (2003), "A homothetic utility function for monopolistic competition models, without constant price elasticity", Economics Letters 78 (1), pp. 79-86.

[23] Ferrantino, M., and D. Taglioni (2014), "Global Value Chains in the Current Trade Slowdown", World Bank Economic Premise N. 137.

[24] Freund, C. (2009), "The Trade Response to Global Downturns: Historical Evidence", Policy Research Working Paper Series 5015, World Bank, Washington, DC.

[25] Gangnes, B., A. Ma, and A. Van Assche (2014), "Global value chains and trade elasticities", Economics Letters 124, pp. 482-486. 
[26] Garcia, C., E. Gordo, J. Martinez-Martin, P. Tello (2009) "Updating import and export functions for the Spanish economy", Banco de España Occasional Papers 0905.

[27] Gaulier, G., Santoni, G., Taglioni, D., and S.Zignago (2015), "The power of the few in determining trade accelerations and slowdowns", in B Hoekman (ed.), The Global Trade Slowdown: A New Normal?, A VoxEU eBook, London: CEPR Press and EUI.

[28] Goldstein, M., and S. Kahn (1985), "Income and price effects in Foreign Trade", in R. W. Jones and P.N. Kenen (eds), Handbook of International Economics, chapter 20, vol. 2, NorthHolland, Amsterdam.

[29] Helpman, E., Melitz, MJ., and SR. Yeaple (2004) "Export versus FDI with heterogeneous firms", American Economic Review 94(1), pp. 300-316.

[30] Hoekman, B. (2015), The Global Trade Slowdown: A New Normal?. VoxEU ed., CEPR.

[31] Hooper, P., Johnson, K., and J. Marquez (2000), "Trade elasticities for G7 countries", International Economics, Vol. 87, Princeton.

[32] Irwin, D. (2002), "Long-run trends in world trade and income", World Trade Review 1(1), pp. 89-100.

[33] Jääskelä, J., and T. Mathews (2015), "Explaining the slowdown in Global Trade". Reserve Bank of Australia Bulletin, Sept, pp. 39-46.

[34] Lejour, A., Rojas-Romagosa, H., and P. Veenendaal (2015), "Identifying hubs and spokes in global supply chains using redirected trade in value added", ECB Working Paper No.1670.

[35] Marquez, J. (1999), "Long-period trade elasticities for Canada, Japan, and the United States", Review of International Economics 7(1), pp. 102-116.

[36] Milberg, W., and D. Winkler (2010), "Trade crisis and recovery : restructuring of global value chains,"Policy Research Working Paper Series 5294, The World Bank.

[37] Ollivaud, P., and C. Schwellnus (2015), "Does the Post-Crisis Weakness of Global Trade Solely Reflect Weak Demand?", OECD Economic Department Working Paper, No 1216.

[38] Pesaran, MH., and RP. Smith (1995), "Estimating long-run relationships from dynamic heterogeneous panels", Journal of Econometrics (68), pp. 79-113.

[39] Pesaran, MH.,, Shin, Y., and RP. Smith (1999), "Pooled mena group estimation of dynamic heterogenous panels", Journal of the American Statistical Association (94), pp. 621-634. 
[40] Slopek, U. (2015), "Why has the income elasticity of global trade declined?", Deutsche Bundesbank, mimeo.

[41] Srinivasan, M., T. Stank, P. Dornier, and K. Petersen (2014), "Global supply chains: Evaluating regions on an EPIC Framework - Economy, Politics, Infraestructure, and Competence", New Work: McGraw-Hill.

[42] Stank, T., M. Burnette, and P. Dittman (2014) "Global supply chains", GSCI-EPIC working paper.

[43] Stratford, K. (2015), "Explaining the structural slowdown in world trade", Bank of England Econ Bulletin.

[44] Veenendaal, P., Lejour, A., Rojas-Romagosa, H., and H. Kox (2015), "A value-added trade perspective on recent patterns in world trade", in B Hoekman (ed.), The Global Trade Slowdown: A New Normal?, A VoxEU eBook, London: CEPR Press and EUI.

[45] Westerlund, J. (2007), "Testing for error correction in panel data". Oxford Bulletin of Economics and Statistics 69: 709-748.

[46] World Trade Organization Annual Report (1996). Special Report on Foreign Direct Investment. 


\section{Appendix}

\subsection{Theory: Import demand functions}

To frame the theoretical foundation of our import-adjusted demand approach with an unrestricted elasticity, we draw our attention to the seminal approach of Goldstein and Kahn (1985), based on the concept of the production possibilities frontier. We also follow the more recent theoretical framework of Feenstra (2003a, and 2003b); however, we have eventually considered imports as demand-driven in line with Bussière et al. (2013).

Assuming that the total output $(G D P)$ function can be written as a function of prices ${ }^{28}$, and thus let $Y$ be the vector of outputs, $P$ the price vector of outputs ${ }^{29}, M$ imports, $P_{M}$ the price vector of imports, and $F$, the vector of primary factors of production. Given a convex technology $T$ (function of $Y, M$, and $F$ ), the efficient economy assumed to determine outputs of individual goods and imports to maximize total output $(G D P)$ subject to prices and the endowments of primary factors. Let $G D P$ be described by the function $v(\cdot)$ of $P, P_{M}$, and $F$ defined as:

$$
v\left(P, P_{M}, F\right) \equiv \max _{Y, M} P Y-P_{M} M \mid Y \in T(Y, M, F),
$$

in this set up, the demand for imports is given by the partial derivative $-v_{P_{M}}\left(P, P_{M}, F\right)$, while the supply of output is given by $v_{P}\left(P, P_{M}, F\right)$. Once we use the market clearing condition for output, $v_{P}\left(P, P_{M}, F\right)=D$, where $D$ is the demand vector. Once we consider the new $G D P$ function $V\left(D, P_{M}, F\right)$ as a function of the demand vector $D$, import prices $P_{M}$, and primary factors $F$ are as follows. Let:

$$
\tilde{v}\left(D, P_{M}, F\right) \equiv \min _{P}\left(P, P_{M}, F\right)-P D
$$

The market clearing condition for output is the first-order contidion (FOC) for this problem, which can be solved for the market clearing price. Then we can write the GDP function as:

$$
v\left(D, P_{M}, F\right) \equiv \tilde{v}\left(D, P_{M}, F\right)+D \tilde{v_{D}}\left(D, P_{M}, F\right)
$$

and import demand is thus given by the partial derivative:

$$
M\left(D, P_{M}, F\right)=-v_{P_{M}}\left(D, P_{M}, F\right)
$$

We can obtain the target import demand equation by imposing the translog assumption directly

\footnotetext{
${ }^{28}$ For the sake of simplicity, we omit time indices.

${ }^{29}$ All prices are in real terms.
} 
on the import demand function $M=-v_{P_{M}}\left(D, P_{M}, F\right)$. Thus

$$
\begin{aligned}
& \ln M=\alpha+\sum_{k} \beta_{k} \ln D_{k}+\beta_{p} \ln P_{M}+\sum_{f} \beta_{f} \ln F_{f}+\frac{1}{2} \sum_{k} \sum_{j} \lambda_{k j} \ln D_{k} \ln D_{j}+\frac{1}{2} \lambda_{p}^{2}\left(\ln P_{M}\right)^{2} \\
& +\frac{1}{2} \sum_{f} \sum_{h} \lambda_{f h} \ln F_{f} \ln F_{h}+\sum_{k} \sum_{f} \theta_{k f} \ln D_{k} \ln F_{f}+\ln P_{M} \sum_{k} \theta_{k} \ln D_{k}+\ln P_{M} \sum_{f} \theta_{f} \ln F_{f}
\end{aligned}
$$

where $\beta_{p}<0$. All in all, the import-based regression follows from first-differencing the import demand translog function under the assumption that second-order terms and factor endowments are constant over time. Including time indices and allowing for time variation in the coefficients $\beta_{k}$, this yields

$$
\Delta \ln M_{t}=\sum_{k} \Delta\left(\beta_{k, t} \ln D_{k, t}\right)+\beta_{p} \Delta \ln P_{M^{*}},
$$

assuming next that $\beta_{k, t}=\beta_{D} \mu_{k, t}$ we obtain that

$$
\Delta \ln M_{t}=\beta_{D} \Delta \ln I A D_{t}+\beta_{p} \Delta \ln P_{M, t^{*}}
$$

Except for the constant included in the regression and the error term, this is again the traditional benchmark regression equation with import-adjusted demand by GDP components.

\subsection{Asymmetries}

From a policy point of view it is also important to assess whether the influence of import-adjusted demand pressure on import outcomes is an effect which appears only during economic expansions or whether there is a trade-off between domestic sales and imports during recession periods. In order to investigate such non-linearity, we test for the existence of an asymmetric relationship between our import-adjusted demand measure and imports by splitting the former into two different variables, depending on its change being positive $(\Delta I A D+)$ or negative $(\Delta I A D-)$ in two quarters running, that is:

$$
\begin{aligned}
& \Delta I A D_{t, t+1}^{+}=\left\{\begin{array}{ll}
1 & \text { if } \Delta I A D_{t, t+1}>0 \\
0 & \text { if } \Delta I A D_{t, t+1}<0
\end{array},\right. \\
& \Delta I A D_{t, t+1}^{-}=\left\{\begin{array}{cc}
1 & \text { if } \Delta I A D_{t, t+1}<0 \\
0 & \text { if } \Delta I A D_{t, t+1}>0
\end{array},\right.
\end{aligned}
$$

In Table 6 the results of panel estimation models allowing for the asymmetric impact of importadjusted demand on import performance are summarised. As can be observed, the influence of the import-adjusted demand cycle becomes irrelevant in the long run. However, it has a noticeable 
asymmetric reaction in the short-term. In times in which the import-adjusted demand decreases, its sensitivity to imports becomes higher than in expansion regimes. It supports, partially, the idea of a trade-off between domestic sales and imports during recession periods, but only in the short run. To sum up, these findings are in line with Bussière et al. (2013), which showed that, during recessions, imports fall by a larger magnitude than private consumption, and a similar magnitude to investment.

\section{Acknowledgements}

I would like to thank A. Al-Haschimi, A. Borin, M. Bussière, J.Ll. Carrión-i-Silvestre, P. del Río, A. Estrada, J. Gonzalo, I. Hernando, J. de Lucio, M. Mancini, D. Santabárbara, U. Slopek, W. Steingress, N. Yamano and seminar participants at Banco de España, at the European Central Bank and at the 4NCBs Workshop (München) for their helpful comments. Special thanks to Enrique Martinez for his excellent research assistance and an anonymous referee, whose valuable comments have substantially improved the paper. 
Table 1: Descriptive statistics

\begin{tabular}{lccccc}
\hline \hline & All countries $(27)$ & & & & \\
\hline & Observations & Mean & Std.Dev. & Min & Max \\
\hline Imports & 5035 & 3.92 & 0.88 & 0.49 & 5.55 \\
Gross Domestic Product $(G D P)$ & 5135 & 4.24 & 0.50 & 2.06 & 5.17 \\
Import-adjusted demand (IAD) & 5031 & 4.15 & 0.61 & 1.46 & 5.30 \\
$\quad$ Exports & 5035 & 3.89 & 0.92 & 0.10 & 5.79 \\
Consumption & 5035 & 4.27 & 0.48 & 2.53 & 5.12 \\
Investment & 5135 & 4.20 & 0.53 & 1.43 & 5.35 \\
Govt. consumption & 5031 & 4.29 & 0.51 & 2.10 & 5.24 \\
Domestic Demand $(D D)$ & 5035 & 4.21 & 0.61 & 0.01 & 5.11 \\
Relative import prices & 4841 & 0.26 & 0.29 & -0.36 & 1.59 \\
GDP deflator & 5126 & 57.4 & 36.9 & 0 & 169.3 \\
Stock of inward investment $(F D I)$ & 3376 & 8.9 & 3.3 & 0 & 15.1 \\
Intermediate imported goods $(G V C)$ & 2592 & 18.0 & 1.1 & 13.7 & 20.9 \\
Protectionist measures $(P T)$ & 5035 & 3.8 & 24.9 & 0 & 238.6 \\
\hline
\end{tabular}

Note: The table presents the log difference of all variables except the protectionist indicator.The statistics are reported in percent units. The dataset covers quarterly data from 1960:I to 2015:I.

Sources: OECD, UNCTAD, Global Trade Alert and The World Bank. 
Table 2: Panel ECM: Estimation results

\begin{tabular}{|c|c|c|c|c|}
\hline & $D D$ & $G D P$ & $I A D$ & By component \\
\hline$\alpha_{i}$ & $-0.168^{* * *}$ & $-0.197^{* * *}$ & $-0.111^{* * *}$ & $-0.083^{* * *}$ \\
\hline$\gamma_{i}(E C)$ & $-0.038^{* * *}$ & $-0.063^{* * *}$ & $-0.072^{* * *}$ & $-0.128^{* * *}$ \\
\hline \multicolumn{5}{|c|}{ LONG - RUN } \\
\hline$\mu_{i}(R M P)$ & $-0.403^{* * *}$ & $-0.477^{* * *}$ & $-0.393^{* * *}$ & $-0.287^{* * *}$ \\
\hline$\rho_{i}(I A D)$ & $1.969^{* * *}$ & $1.725^{* * *}$ & $1.370^{* * *}$ & \\
\hline Exports & & & & $0.726^{* * *}$ \\
\hline Consumption & & & & $0.286^{* * *}$ \\
\hline Govt.consumption & & & & $-0.067^{* * *}$ \\
\hline Investment & & & & $0.211^{* * *}$ \\
\hline \multicolumn{5}{|c|}{ SHORT - RUN } \\
\hline$\delta_{m}(R M P)$ & 0.041 & $-0.094^{*}$ & $-0.052^{*}$ & $-0.059^{*}$ \\
\hline$\beta_{j}(I A D)$ & $1.439^{* * *}$ & $1.367^{* * *}$ & $1.174^{* * *}$ & \\
\hline Exports & & & & $0.450^{* * *}$ \\
\hline Consumption & & & & $0.653^{* * *}$ \\
\hline Govt.consumption & & & & $0.100^{* * *}$ \\
\hline Investment & & & & $0.321^{* * *}$ \\
\hline LogLikelihood & 10651.7 & 10254.6 & 10816.2 & 11340.6 \\
\hline Nobs & 4798 & 4798 & 4794 & 4798 \\
\hline
\end{tabular}

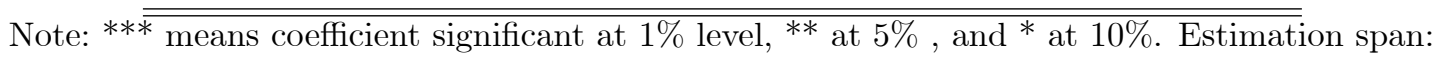
1960Q1 - $2015 \mathrm{Q} 4$. 
Table 3: Panel ECM: Estimation results

\begin{tabular}{|c|c|c|c|c|c|c|}
\hline & $P M G(1)$ & $P M G(2)$ & $P M G(3)$ & $P M G(4)$ & $M G$ & Dynamic_FE \\
\hline$\alpha_{i}$ & $-0.111^{* * *}$ & $-0.139 * * *$ & $-0.150^{* * *}$ & $-0.533^{* * *}$ & $-1.183^{* * *}$ & $-0.162^{* * *}$ \\
\hline$\gamma_{i}(E C)$ & $-0.072^{* * *}$ & $-0.109^{* * *}$ & $-0.114^{* * *}$ & $-0.155^{* * *}$ & $-0.493^{* * *}$ & $-0.109^{* * *}$ \\
\hline \multicolumn{7}{|c|}{ LONG - RUN } \\
\hline$\mu_{i}(R M P)$ & $-0.393^{* * *}$ & $-0.445^{* * *}$ & $-0.447^{* * *}$ & $-0.081^{*}$ & 0.092 & $-0.412^{* * *}$ \\
\hline$\rho_{i}(I A D)$ & $1.370^{* * *}$ & $1.251^{* * *}$ & $1.241^{* * *}$ & $0.865^{* * *}$ & $0.843^{* * *}$ & $1.050^{* * *}$ \\
\hline$\sigma_{i}(F D I)$ & & $0.023^{* * *}$ & $0.023^{* * *}$ & $0.054^{* * *}$ & $0.035^{* * *}$ & $0.039^{* *}$ \\
\hline$\nu_{i}(P T)$ & & & $0.001^{* * *}$ & $0.001^{* *}$ & 0.001 & $0.001^{* * *}$ \\
\hline$w_{i}(G V C)$ & & & & $0.193^{* * *}$ & $0.105^{* * *}$ & 0.046 \\
\hline \multicolumn{7}{|c|}{ SHORT - RUN } \\
\hline$\delta_{m}(\Delta R M P)$ & $-0.052^{*}$ & -0.038 & -0.039 & -0.052 & 0.021 & $-0.167^{* * *}$ \\
\hline$\beta_{j}(\Delta I A D)$ & $1.174^{* * *}$ & $1.216^{* * *}$ & $1.217^{* * *}$ & $1.297^{* * *}$ & $1.300^{* * *}$ & $0.986^{* * *}$ \\
\hline$\delta_{n}(\Delta F D I)$ & & -0.008 & -0.007 & -0.031 & -0.011 & 0.007 \\
\hline$\delta_{p}(\Delta P T)$ & & & -0.001 & -0.001 & $-0.001^{*}$ & -0.001 \\
\hline$\delta_{q}(\Delta G V C)$ & & & & $0.116^{* * *}$ & $0.102^{* * *}$ & $0.049^{*}$ \\
\hline LogLikelihood & 10816.2 & 7008.7 & 7018.9 & 2983.7 & & \\
\hline Nobs & 4794 & 2925 & 2925 & 1111 & 1111 & 1111 \\
\hline
\end{tabular}


Table 4: In-sample country-specific ECM estimates

\begin{tabular}{|c|c|c|c|c|}
\hline & $\sum \Delta \ln (D D)_{t-1}$ & $\sum \Delta \ln (G D P)_{t-1}$ & $\sum \Delta \ln (I A D)_{t-1}$ & $\sum \Delta \ln (R M P)_{t-1}$ \\
\hline USA & 2.78 & 2.51 & 2.00 & -0.15 \\
\hline UK & 1.49 & 1.37 & 1.22 & 0.03 \\
\hline Japan & 1.62 & 1.45 & 1.22 & -0.07 \\
\hline Germany & 1.51 & 1.40 & 1.30 & 0.23 \\
\hline France & 2.28 & 2.16 & 1.68 & -0.08 \\
\hline Italy & 2.31 & 2.17 & 1.66 & -0.24 \\
\hline Canada & 2.21 & 2.11 & 1.61 & -0.21 \\
\hline G7 countries & 1.93 & 1.79 & 1.48 & -0.10 \\
\hline Australia & 1.95 & 1.47 & 1.02 & -0.72 \\
\hline Korea & 1.00 & 1.43 & 1.30 & -0.37 \\
\hline Spain & 2.10 & 2.46 & 1.67 & -0.24 \\
\hline Netherlands & 0.86 & 0.86 & 0.56 & -0.02 \\
\hline Portugal & 2.08 & 2.18 & 1.27 & 0.08 \\
\hline Norway & 0.95 & 1.16 & 0.76 & -0.40 \\
\hline New Zealand & 1.81 & 0.40 & 1.01 & -0.12 \\
\hline Sweden & 2.12 & 1.93 & 1.41 & 0.23 \\
\hline Belgium & 1.57 & 1.91 & 1.14 & 0.08 \\
\hline Finland & 1.60 & 1.92 & 1.24 & 0.19 \\
\hline Denmark & 1.58 & 1.72 & 1.25 & 0.10 \\
\hline Austria & 1.01 & 1.75 & 1.40 & 0.01 \\
\hline Greece & 1.23 & 1.71 & 1.15 & -0.41 \\
\hline Hungary & 1.71 & 2.65 & 1.96 & -0.11 \\
\hline Iceland & 1.31 & 0.81 & 1.04 & -0.36 \\
\hline Israel & 2.37 & 2.12 & 1.55 & 0.09 \\
\hline Mexico & 1.90 & 2.32 & 1.31 & -0.05 \\
\hline Slovenia & 0.24 & 2.18 & 1.37 & 0.33 \\
\hline Switzerland & 2.03 & 1.81 & 1.53 & -0.13 \\
\hline Ireland & 1.17 & 0.91 & 1.12 & 0.66 \\
\hline Panel (All countries) & 1.96 & 1.72 & 1.37 & -0.39 \\
\hline
\end{tabular}


Table 5: Panel ECM: Estimation results by regime

\begin{tabular}{lccc}
\hline \hline & First regime & Second regime & Third regime \\
& $(1960-2000)$ & $(2001-2009)$ & $(2010-2015)$ \\
\hline$\alpha_{i}$ & $-0.276^{* * *}$ & $-0.784^{* * *}$ & $-0.149^{* * *}$ \\
$\gamma_{i}(E C)$ & $-0.192^{* * *}$ & $-0.369^{* * *}$ & $-0.233^{* * *}$ \\
\hline \multicolumn{4}{c}{ LONG - RUN } \\
\hline$\mu_{i}(R M P)$ & $-0.375^{* * *}$ & $-0.096^{* * *}$ & $-0.472^{* * *}$ \\
$\rho_{i}(I A D)$ & $1.361^{* * *}$ & $1.460^{* * *}$ & $1.188^{* * *}$ \\
\hline \multicolumn{4}{c}{ SHORT - RUN } \\
\hline$\delta_{m}(\Delta R M P)$ & -0.082 & 0.053 & 0.153 \\
$\beta_{j}(\Delta I A D)$ & $1.098^{* * *}$ & $1.122^{* * *}$ & $1.410^{* * *}$ \\
\hline LogLikelihood & 7548.77 & 1947.03 & 1934.88 \\
Nobs & 3359 & 702 & 760 \\
\hline Note: ${ }^{* * *}$ means coefficient significant at 1\% level, ${ }^{* *}$ at $5 \%$, and ${ }^{*}$ at &
\end{tabular}

Table 6: Panel ECM: Estimation results with asymmetries in import-adjusted measure

\begin{tabular}{lcc}
\hline \hline & IAD in expansion & IAD in recession \\
\hline$\alpha_{i}$ & $-0.096^{* * *}$ & $-0.107^{* * *}$ \\
$\gamma_{i}(E C)$ & $-0.064^{* * *}$ & $-0.066^{* * *}$ \\
\hline \multicolumn{3}{c}{ LONG $-\mathbf{R U N}$} \\
\hline$\mu_{i}(R M P)$ & $-0.440^{* * *}$ & $-0.427^{* * *}$ \\
$\rho_{i}(I A D)$ & $1.363^{* * *}$ & $1.366^{* * *}$ \\
\hline \multicolumn{3}{c}{$\mathbf{S H O R T}-\mathbf{R U N}$} \\
\hline$\delta_{m}(\Delta R M P)$ & $-0.075^{*}$ & -0.012 \\
$\beta_{j}(\Delta$ IAD $)$ & $1.096^{* * *}$ & $1.268^{* * *}$ \\
\hline LogLikelihood & 8438.35 & 2575.69 \\
Nobs & 3607 & 1187 \\
\hline \hline
\end{tabular}

Note: $* * * \overline{\overline{\text { means coefficient significant at } 1 \% \text { level, }{ }^{* *} \text { at } 5 \%, \text { and }}} *$ at $10 \%$. 
Figure 1: World trade and output (Volumes)

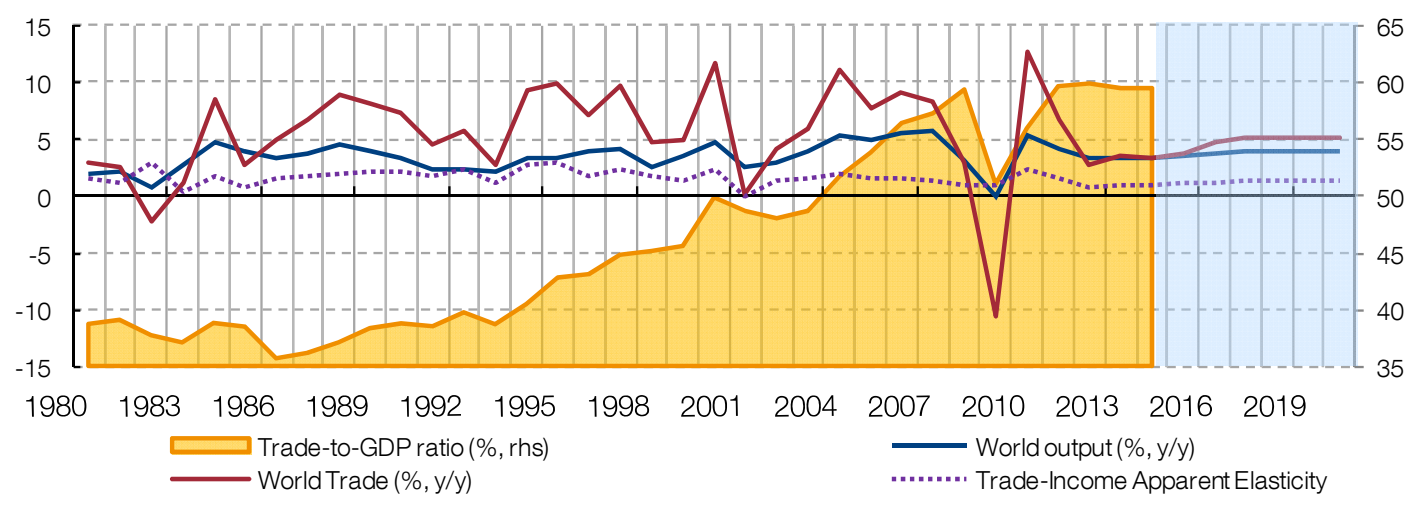

Notes. The blue-shaded area corresponds to IMF projections.

Source: IMF World Economic Outlook - April 2016. World Bank WDI Database and author's calculations.

Figure 2: Import volumes of emerging economies.

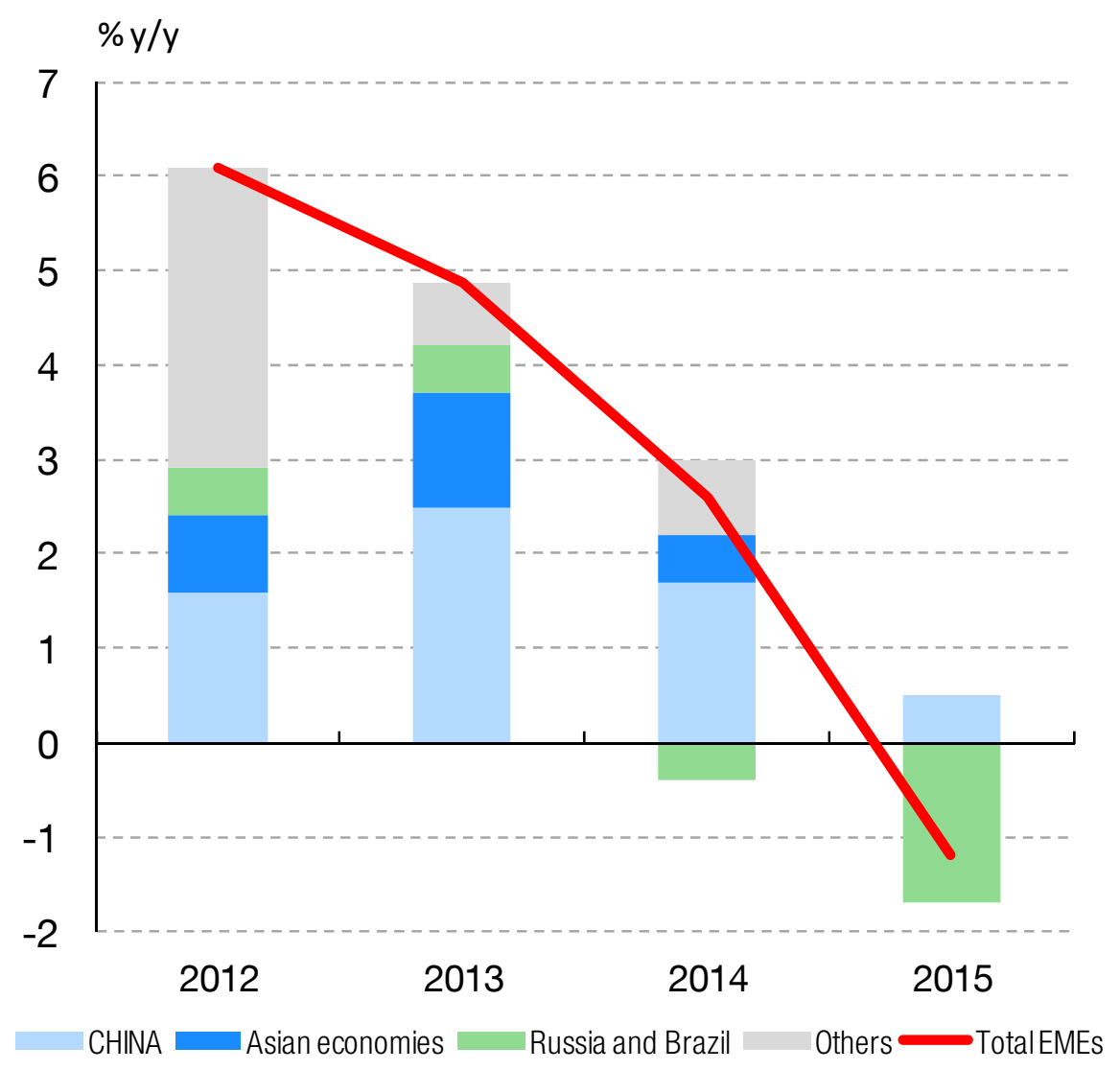

Source: OECD 
Figure 3: Trade-income elasticity: GDP vs. Import-adjusted demand (IAD) by GDP components.

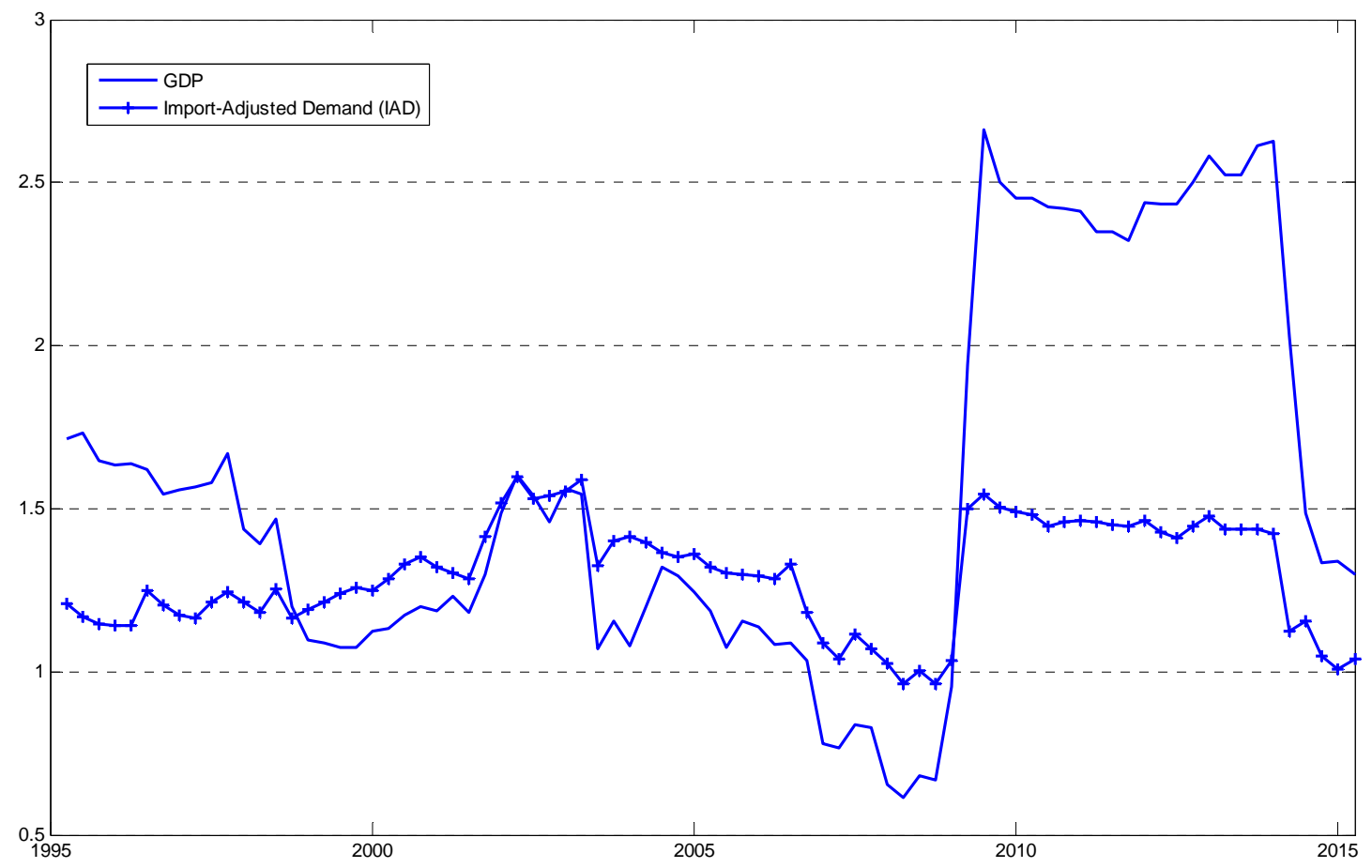

Source: Author's calculations based on 5-year rolling window panel estimates of the form: $\Delta \ln M_{i, t}=\delta_{i}+\beta_{1} \Delta \ln I A D_{i, t}+\beta_{2} \Delta \ln R M P_{i, t}+\beta_{3} \Delta \ln I A D_{i, t-1}+\beta_{4} \Delta \ln R M P_{i, t-1}+\beta_{5} \Delta \ln M_{i, t-1}+\varepsilon_{i, t}$

Figure 4. Model fitness when using different aggregate demand measures.

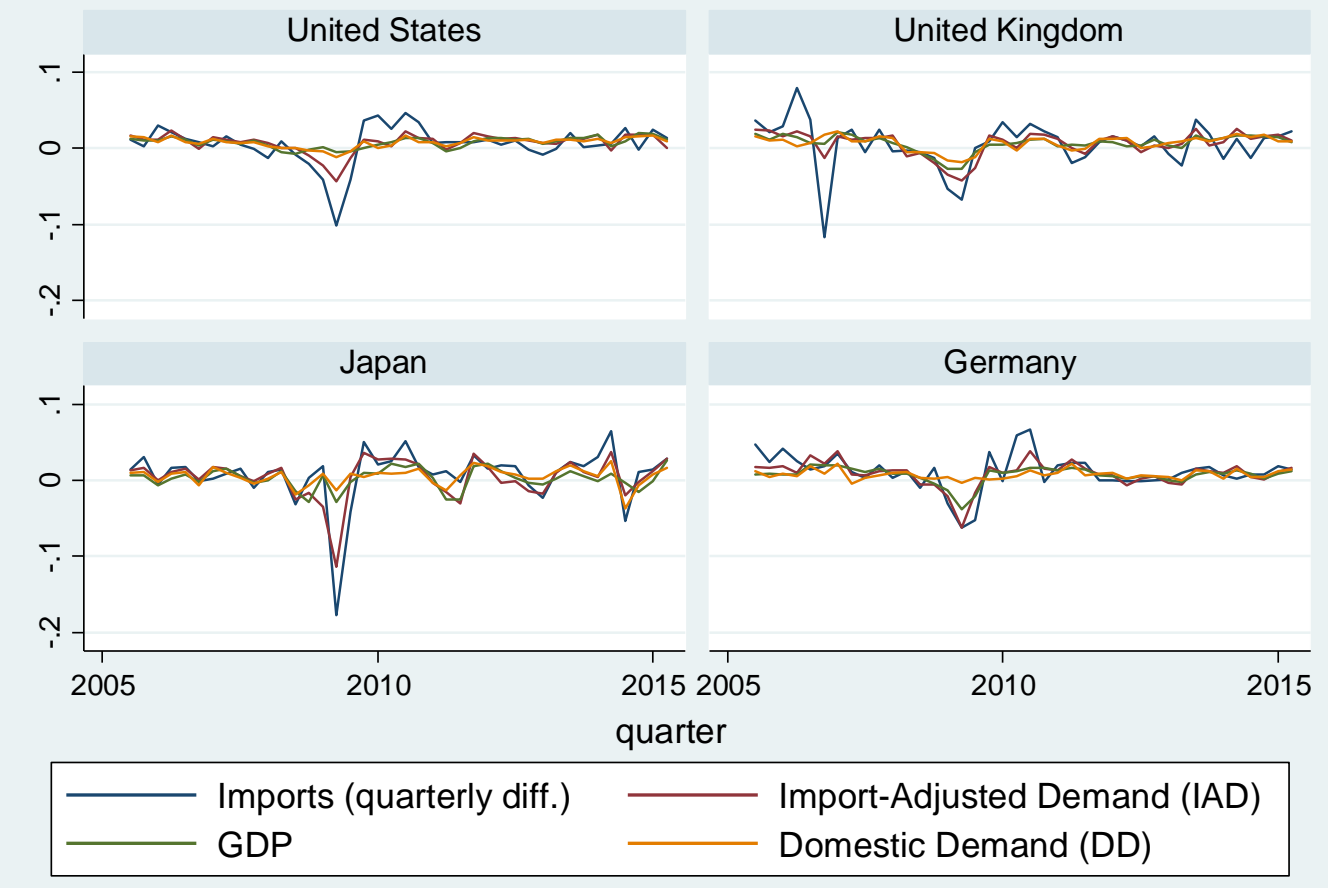

Graphs by id

Source: Author's calculations based on:

$\Delta \ln M_{i, t}=\delta_{i}+\beta_{1} \Delta \ln I A D_{i, t}+\beta_{2} \Delta \ln R M P_{i, t}+\beta_{3} \Delta \ln I A D_{i, t-1}+\beta_{4} \Delta \ln R M P_{i, t-1}+\beta_{5} \Delta \ln M_{i, t-1}+\varepsilon_{i, t}$ 
Figure 5: Import contents of main GDP components for the G7

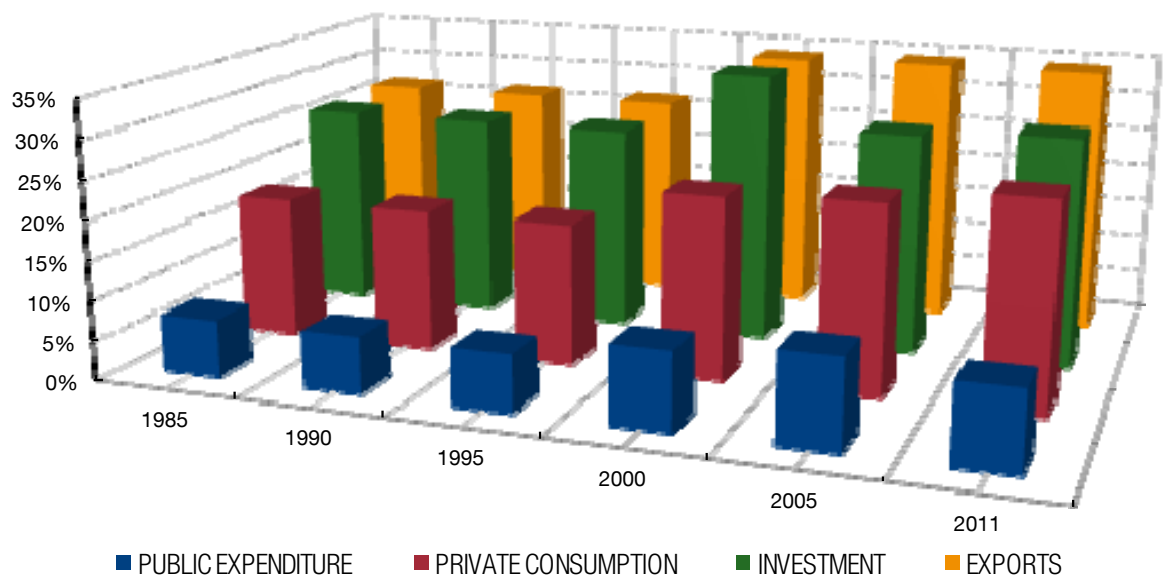

Source: OECD Input-Output tables and author's calculations.

Figure 6: Long-term demand elasticity by GDP component

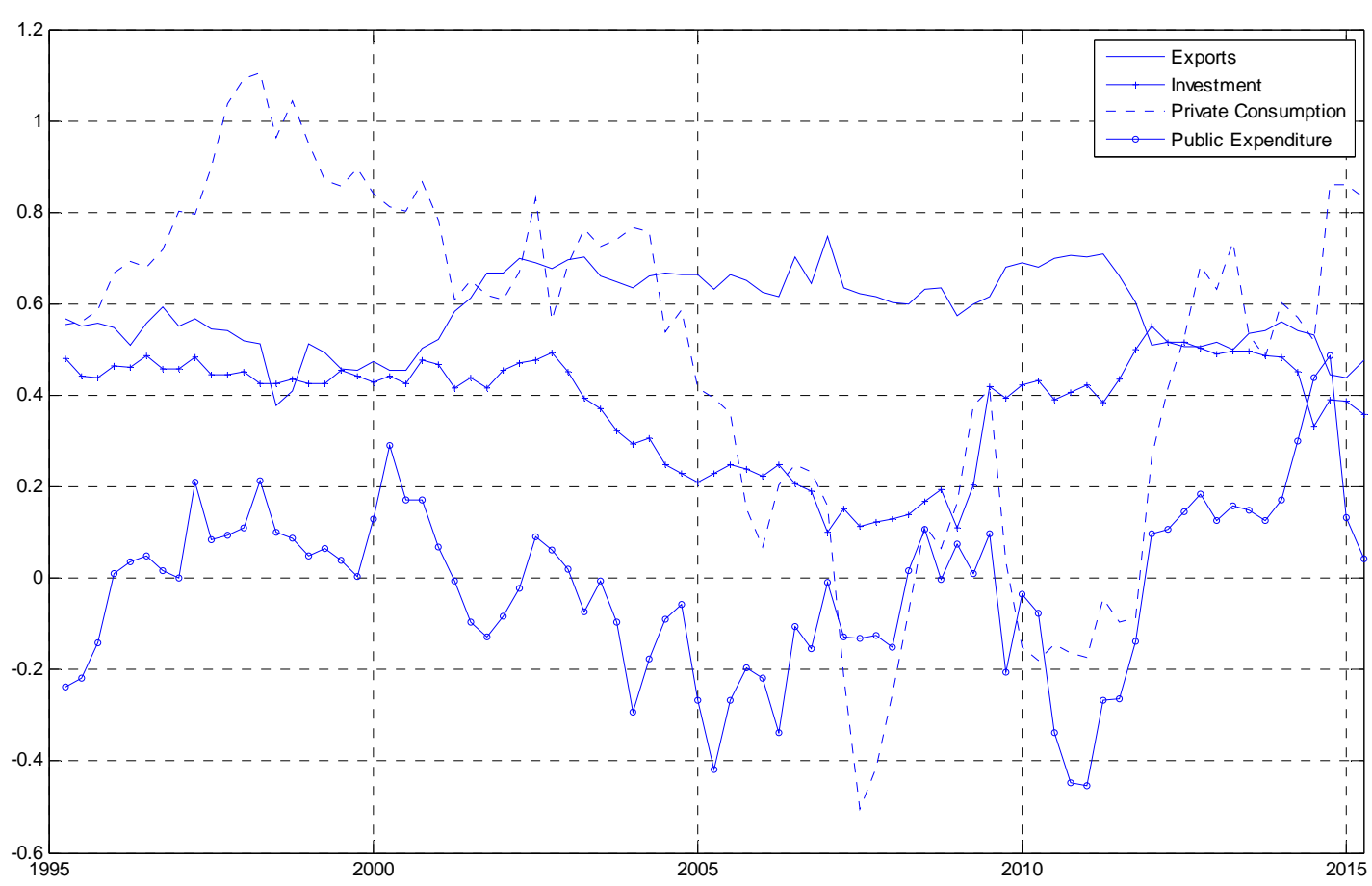

Notes. 5-year rolling window panel estimates of the form: $\Delta \ln M_{i, t}=\delta_{i}+\beta_{C} \Delta \ln C_{i, t-1}+\beta_{X} \Delta \ln X_{i, t-1}+$ $\beta_{I} \Delta \ln I_{i, t-1}+\beta_{G} \Delta \ln G_{i, t-1}+\beta_{P} \Delta \ln R M P_{i, t-1}+\varepsilon_{i, t}$ for the G7 countries.

Source: Author's calculations. 
Figure 7: Contributions to quarterly import growth by cyclical component

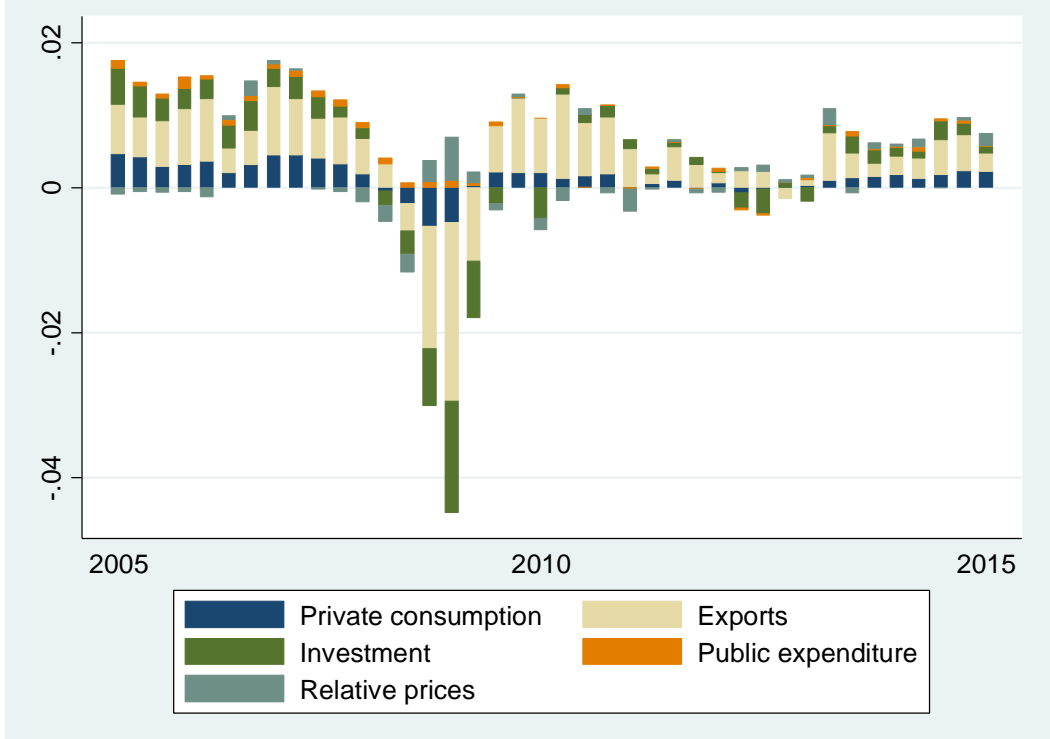

Source: Author's calculations.

Notes. Structural variables and residuals are not included.

$\Delta \ln M_{i, t}=\delta_{i}+\beta_{C} \Delta \ln C_{i, t-1}+\beta_{X} \Delta \ln X_{i, t-1}+\beta_{I} \Delta \ln I_{i, t-1}+\beta_{G} \Delta \ln G_{i, t-1}+\beta_{P} \Delta \ln R M P_{i, t-1}+\varepsilon_{i, t}$

Figure 8: Contributions to quarterly import growth by component

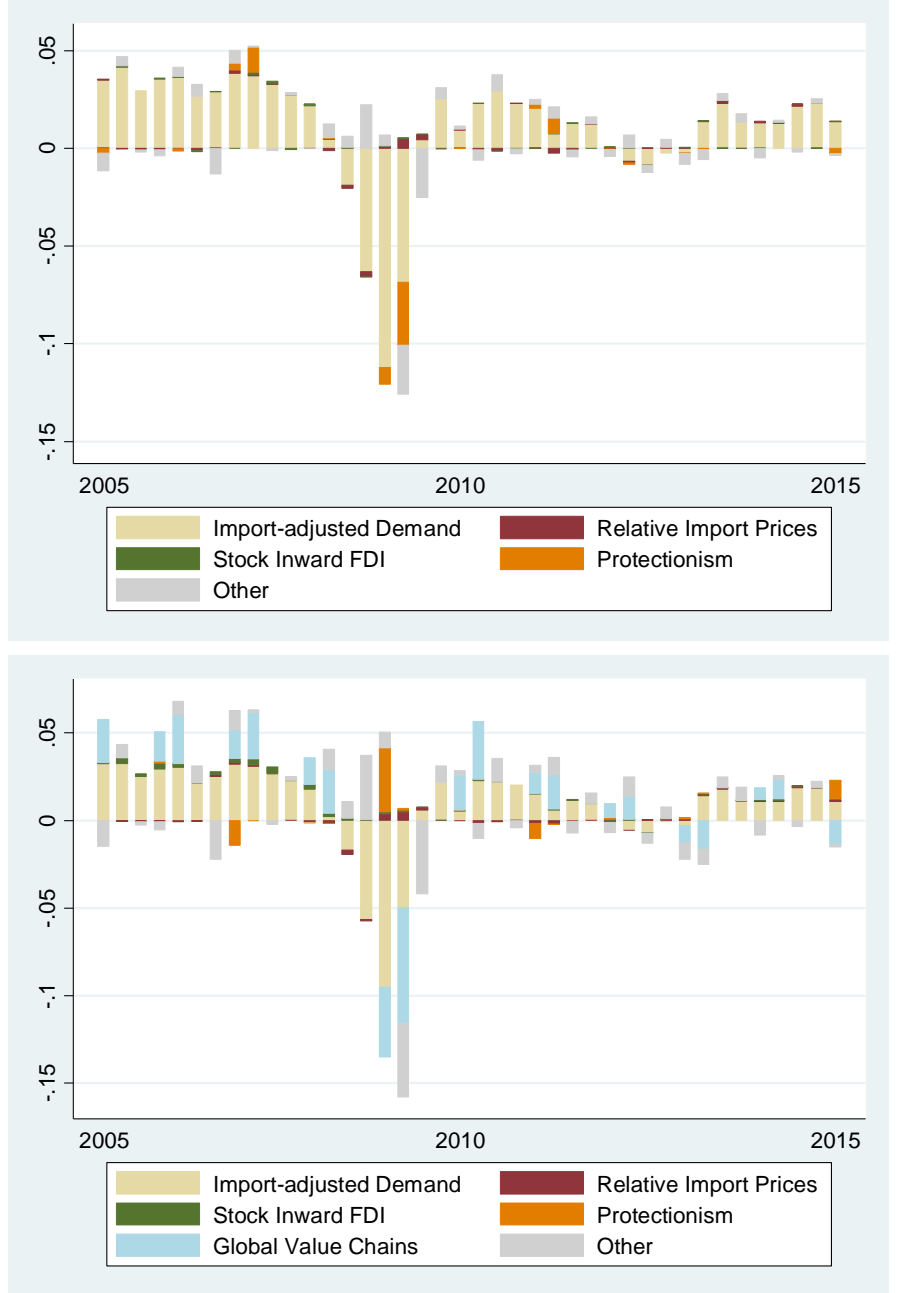

Source: Author's calculations.

Notes. Based on the Panel ECM regression (Eq. 3) 
Figure 9: Frequency of the estimated heterogeneous break dates (year and quarter) for 21 countries

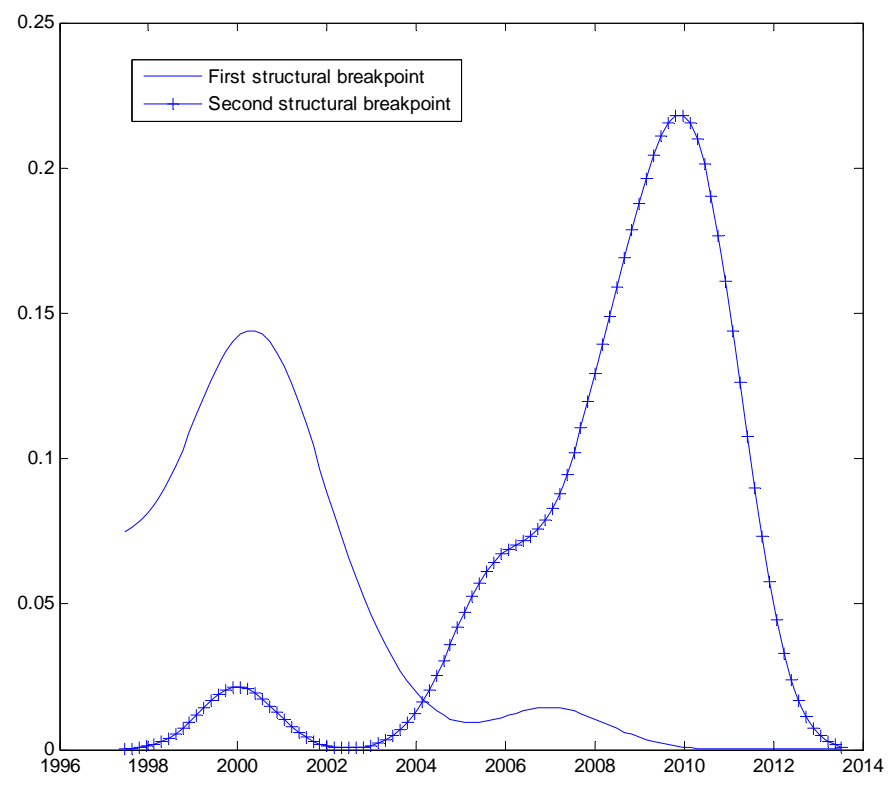

Source: Author's calculations.

Figure 10: Frequency of the estimated heterogeneous break dates by GDP component
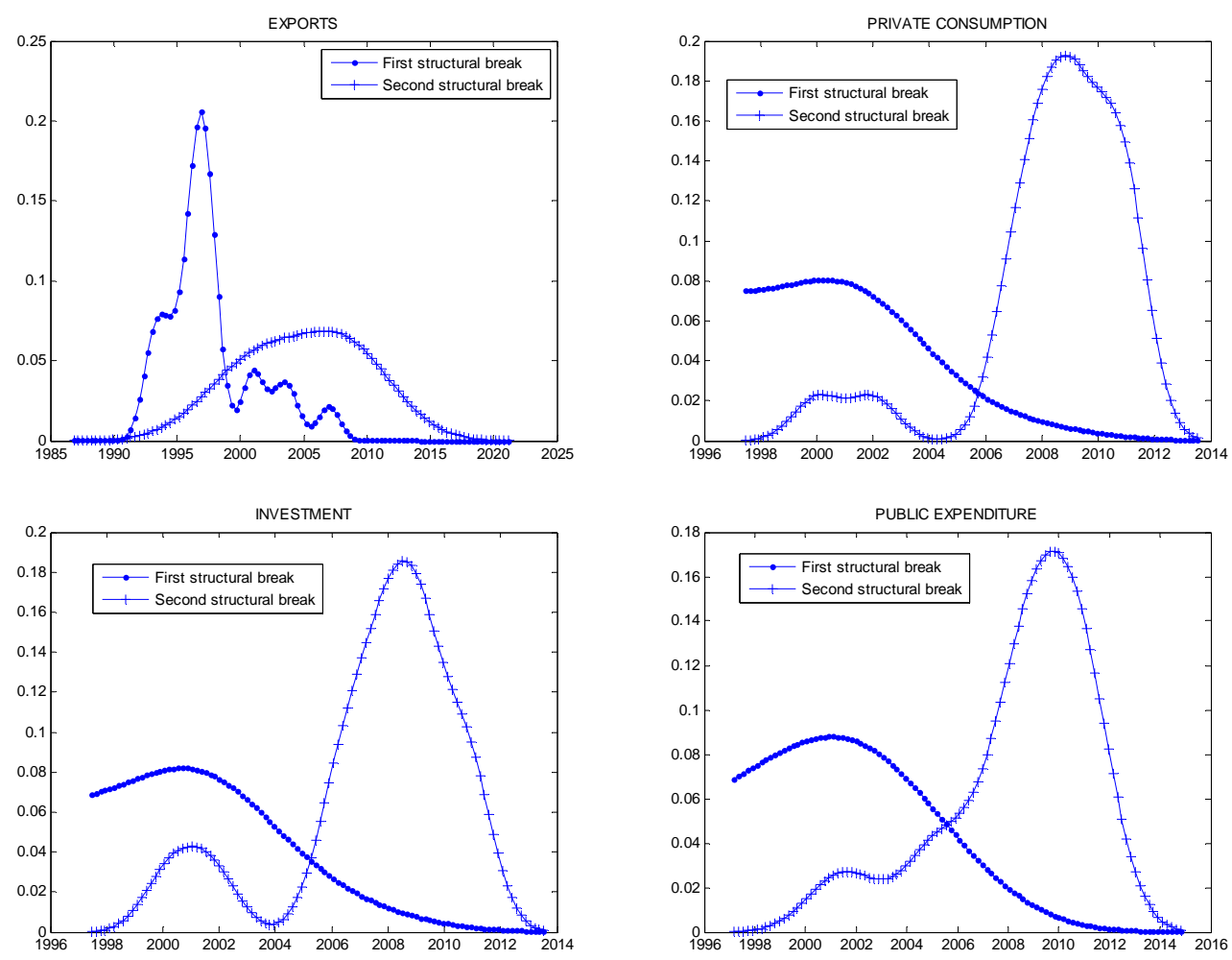

Source: Author's calculations. 
Figure 11. Densities of the estimated coefficients for the three regimes.
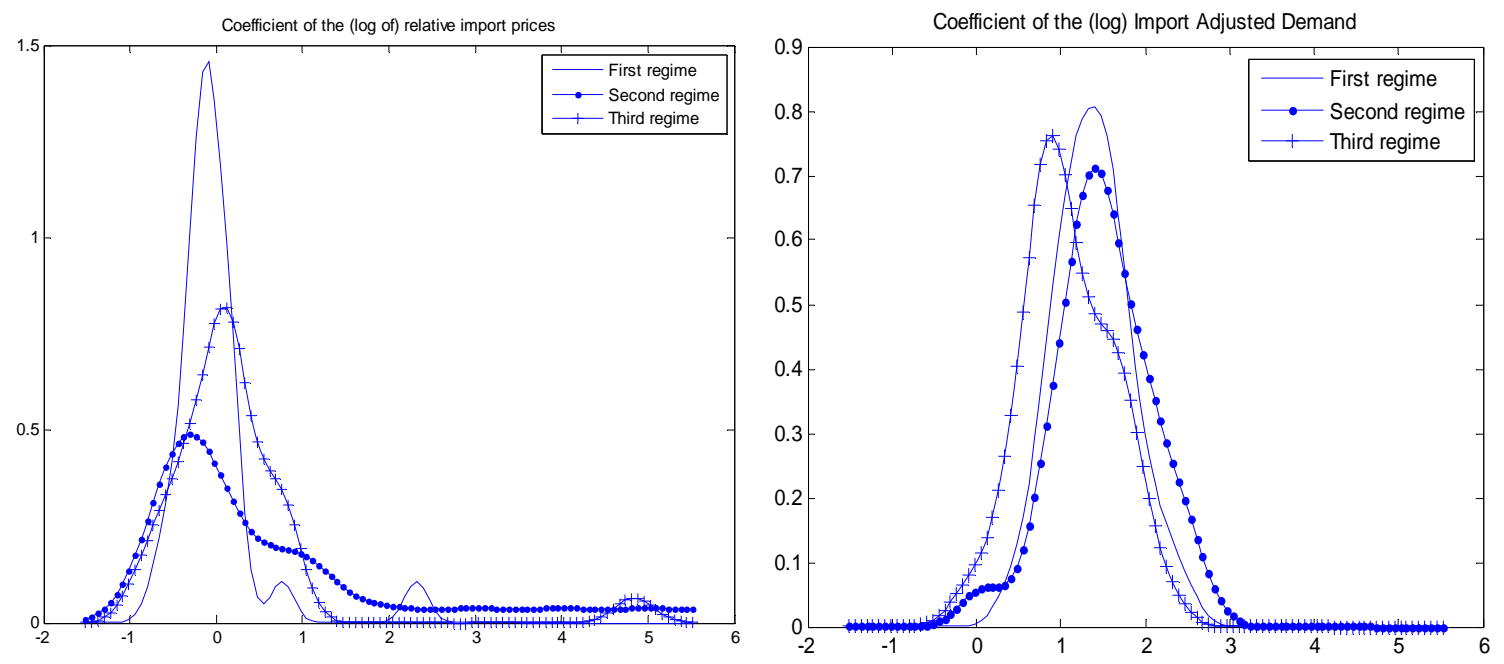

Source: Author's calculations.

Notes. Estimated break dates for the units for which the null hypothesis of no cointegration is rejected at the $5 \%$ level of significance in the unit-by-unit analysis.

Figure 12. Decomposition of quarterly import growth into short vs. long-term components.

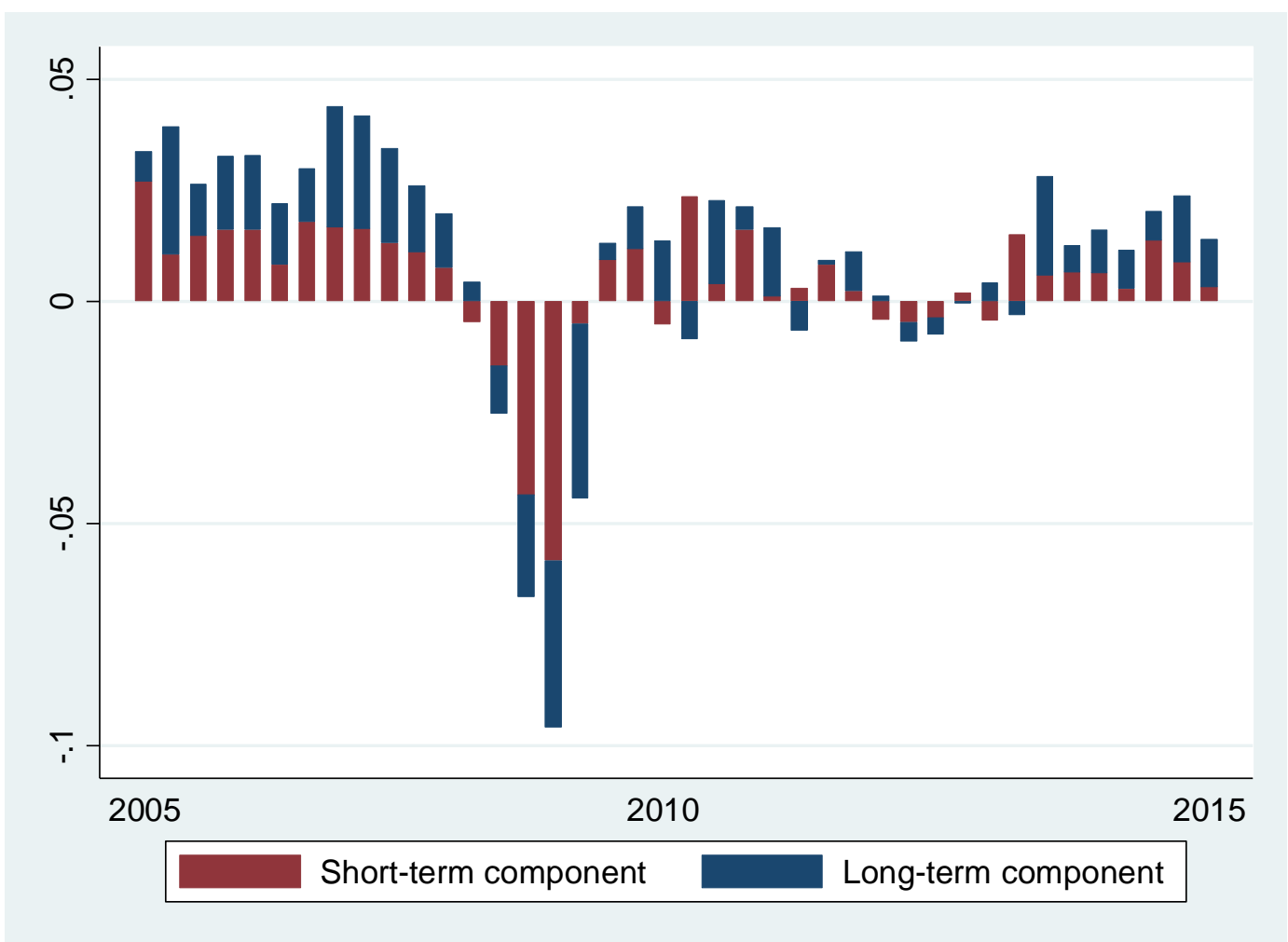

Source: Author's calculations.

Notes. Residuals from panel ECM estimations are not included. 